This item was submitted to Loughborough's Research Repository by the author.

Items in Figshare are protected by copyright, with all rights reserved, unless otherwise indicated.

\title{
Objective extraction of channel heads from high-resolution topographic data
}

\section{PLEASE CITE THE PUBLISHED VERSION}

http://dx.doi.org/10.1002/2013WR015167

\section{PUBLISHER}

(c) American Geophysical Union

\section{VERSION}

VoR (Version of Record)

\section{PUBLISHER STATEMENT}

This work is made available according to the conditions of the Creative Commons Attribution-NonCommercialNoDerivatives 4.0 International (CC BY-NC-ND 4.0) licence. Full details of this licence are available at: https://creativecommons.org/licenses/by-nc-nd/4.0/

\section{LICENCE}

CC BY-NC-ND 4.0

\section{REPOSITORY RECORD}

Clubb, Fiona J., Simon M. Mudd, David T. Milodowski, Martin D. Hurst, and Louise Slater. 2019. "Objective Extraction of Channel Heads from High-resolution Topographic Data". figshare.

https://hdl.handle.net/2134/23991. 


\section{Water Resources Research}

\section{RESEARCH ARTICLE Objective extraction of channel heads from high-resolution 10.1002/2013WR015167 topographic data}

Key Points:

-We have compared methods of channel head prediction with fieldmapped channel networks

-We present a new method of channel head extraction with two userdefined parameters

- Our method predicts channel heads based on theoretical laws of sediment transport

Correspondence to:

F. J. Clubb,

F.Clubb@ed.ac.uk

Citation:

Clubb, F. J., S. M. Mudd, D. T.

Milodowski, M. D. Hurst, and L. J. Slater (2014), Objective extraction of channel heads from high-resolution topographic data, Water Resour. Res., 50, doi:10.1002/2013WR015167.

Received 11 DEC 2013

Accepted 22 APR 2014

Accepted article online 28 APR 2014

\author{
Fiona J. Clubb1, Simon M. Mudd1', David T. Milodowski', Martin D. Hurst², and Louise J. Slater \\ ${ }^{1}$ School of Geosciences, University of Edinburgh, Edinburgh, UK, ${ }^{2}$ British Geological Survey, Keyworth, Nottinghamshire, \\ UK, ${ }^{3}$ Department of Earth and Environmental Sciences, University of St Andrews, St Andrews, Fife, UK
}

\begin{abstract}
Fluvial landscapes are dissected by channels, and at their upstream termini are channel heads. Accurate reconstruction of the fluvial domain is fundamental to understanding runoff generation, storm hydrology, sediment transport, biogeochemical cycling, and landscape evolution. Many methods have been proposed for predicting channel head locations using topographic data, yet none have been tested against a robust field data set of mapped channel heads across multiple landscapes. In this study, four methods of channel head prediction were tested against field data from four sites with high-resolution DEMs: slopearea scaling relationships; two techniques based on landscape tangential curvature; and a new method presented here, which identifies the change from channel to hillslope topography along a profile using a transformed longitudinal coordinate system. Our method requires only two user-defined parameters, determined via independent statistical analysis. Slope-area plots are traditionally used to identify the fluvialhillslope transition, but we observe no clear relationship between this transition and field-mapped channel heads. Of the four methods assessed, one of the tangential curvature methods and our new method most accurately reproduce the measured channel heads in all four field sites (Feather River CA, Mid Bailey Run $\mathrm{OH}$, Indian Creek $\mathrm{OH}$, Piedmont VA), with mean errors of $-11,-7,5$, and $-24 \mathrm{~m}$ and 34, 3, 12, and $-58 \mathrm{~m}$, respectively. Negative values indicate channel heads located upslope of those mapped in the field. Importantly, these two independent methods produce mutually consistent estimates, providing two tests of channel head locations based on independent topographic signatures.
\end{abstract}

\section{Introduction}

Fluvial landscapes are dissected by channels and at the upstream termini of these channels are channel heads. Their position controls the total length of channels in the stream network, which sets drainage density and therefore influences biogeochemical cycling, and water and sediment flux to the river system [Montgomery and Dietrich, 1989; Julian et al., 2012; Jefferson and McGee, 2013]. Their location also determines the speed at which pollutants may enter the river network if located close to areas of anthropogenic land use such as industry or mining [Novotny, 2002]. Therefore, determining the location of channel heads is essential for flood forecasting, mitigation of pollution, prediction of ecosystem functioning, and landscape evolution.

Channel heads can be defined morphologically as "the upslope limit of erosion and concentration of flow within steepened banks" [Montgomery and Dietrich, 1989]. Field identification of channel heads is difficult and time consuming, so many authors have suggested methods to identify these landscape features using topographic data [O'Callaghan and Mark, 1984; Band, 1986; Montgomery and Dietrich, 1988; Tarboton et al., 1991; Dietrich et al., 1992, 1993; Dietrich and Dunne, 1993; Montgomery and Foufoula-Georgiou, 1993; Molloy and Stepinski, 2007; Tarolli and Dalla Fontana, 2009; Passalacqua et al., 2010; Thommeret et al., 2010; Sofia et al., 2011; Henkle et al., 2011; Orlandini et al., 2011; Pelletier, 2013]. A clear distinction exists between the "channel network," which represents parts of the landscape responding to fluvial incision, and the "valley network," defined as areas of convergent topography [Howard, 1994]. In this study, we focus on methods of extracting the channel network from digital elevation models (DEMs).

Traditionally, channel heads were identified using methods founded on process-based models, such as contributing area thresholds [O'Callaghan and Mark, 1984; Band, 1986; Tarboton et al., 1991] or slope-area scaling relationships [Montgomery and Dietrich, 1988; Dietrich et al., 1992, 1993]. Montgomery and Dietrich [1988] suggested that channels initiate where drainage area is large enough to support a channel and that there is 
an inverse relationship between slope and drainage area downstream of the channel head. However, in steep, rocky landscapes, it may be difficult to distinguish between fluvial channels and steep threshold hillslopes using these scaling relationships [Montgomery and Foufoula-Georgiou, 1993]. Furthermore, the analysis of channel head locations using coarse-resolution ( $30 \mathrm{~m}$ ) DEMs may result in error, as the processes involved in channel initiation act on a meter to submeter scale. Orlandini et al. [2011] extracted slope and drainage area threshold conditions for channel initiation across DEMs of varying resolutions using observed channel heads, and found that the value of the threshold parameters strongly depended on the grid size.

The recent introduction of high-resolution topographic data, such as Airborne Light-Detection and Ranging data (LiDAR) has revolutionized the study of geomorphology, and has allowed fundamental questions about landscape form and evolution to be reassessed. Recent methods of channel head prediction have used LiDAR to predict channel head locations directly from local topographic characteristics. For example, Sofia et al. [2011] used topographic openness, a morphometric character that quantifies the degree of openness or enclosure of a location on an irregular surface, to predict channel heads. Other methods use the tangential curvature to identify the start of the fluvial network from DEMs. The GeoNet 2.0 software, developed by Passalacqua et al. [2010], combines a Perona-Malik filter, to smooth the DEM while preserving hillslope-valley transitions, and a curvature threshold to produce a draft map of the channel head locations. This is improved by creating a valley network based on pathways which minimize a cost function inversely proportional to the threshold curvature and drainage area [Passalacqua et al., 2010]. Another curvaturebased method utilizes an algorithm created by Pelletier [2013], which involves filtering the DEM using an optimal Wiener filter [Wiener, 1949; Press, 2007] and a threshold tangential curvature for channelization. These methods are similar in that they search for a tangential curvature signature in the landscape for the location of the channel network; however, Pelletier's [2013] method requires only two user-defined parameters, whereas GeoNet [Passalacqua et al., 2010] requires five.

In order to demonstrate the success of a method as a predictive tool, it must be tested against a robust field data set. Sofia et al. [2011] tested their algorithm on 57 channel heads across two alpine headwater catchments. Passalacqua et al. [2010] mapped seven channel heads in a subcatchment of the South Fork Eel River basin in northern California to test the GeoNet algorithm. Pelletier [2013] tested his algorithm using a synthetic data set in which channel heads were proscribed within a simple landscape evolution model. Although these previous tests suggest these methods could be used to detect channel heads from DEMs alone, the test data sets had relatively few data points to compare with algorithm output and, crucially, they were not tested across multiple landscapes.

In this study, we test several proposed methods of channel head prediction against field-mapped channel head data from multiple field sites. We test both methods that incorporate theoretical process-based models and those that predict channel heads directly from geometric characteristics of high-resolution DEMs. The methods of channel head identification we evaluate are slope-area scaling relationships [Montgomery and Dietrich, 1988; Orlandini et al., 2011]; the GeoNet 2.0 drainage network extraction algorithm [Passalacqua et al., 2010]; tangential curvature mapping [Pelletier, 2013]; and a new, process-based method of channel head identification that uses a coordinate transformation of flow distance, which we describe in section 3.6. We call our new method the Drainage Extraction by Identifying Channel Heads (DrEICH) method. We test these methods against a total of 167 mapped channel heads in three field areas that are colocated with $1 \mathrm{~m}$ resolution LiDAR data.

\section{Field Setting}

We report channel head locations mapped for this study across two sites in Northern California and two in Southern Ohio, and we also assimilate data from a previous study that was conducted in the Piedmont physiographic region, Virginia, with $1 \mathrm{~m}$ resolution LiDAR [Julian et al., 2012].

\subsection{Feather River, Sierra Nevada, California}

Channel head mapping was undertaken in the lower part of the Middle Fork Feather River in the northern Sierra Nevada, California (Figure 1). Airborne Laser Swath Mapping (ALSM)-derived topographic data were undertaken in the region on 25-27 September 2008 by the National Center for Airborne Laser Mapping [NCALM, www.ncalm.org], with a vertical accuracy of $0.05-0.3 \mathrm{~m}$ and a mean horizontal accuracy of $0.3 \mathrm{~m}$. 

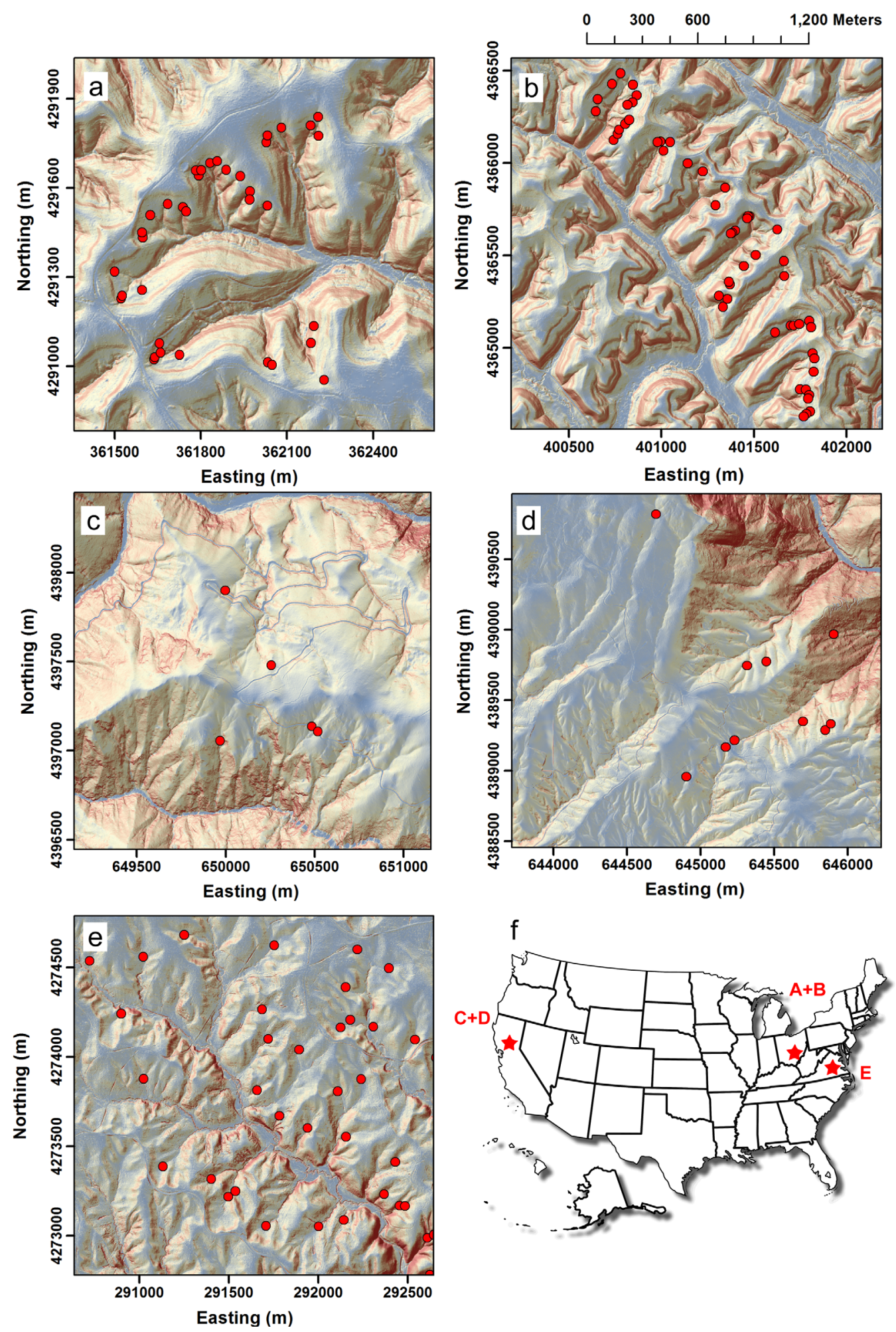

Figure 1. Shaded slope map of each field site with mapped channel heads, along with their location in the USA. (a) Indian Creek, Wayne National Forest, OH, UTM Zone 17N. (b) Mid Bailey Run, Wayne National Forest, OH, UTM Zone 17N. (c) Cascade Ridge, Sierra Nevada, CA, UTM Zone 10N. (d) Bald Rock Basin, Sierra Nevada, CA, UTM Zone 10N. (e) Piedmont, VA, UTM Zone 18N. (f) Map of the USA showing locations of sites in Figures 1a-1e. 
The metadata were made available online by the National Science Foundation's OpenTopography service [www.opentopography.org].

The landscape is largely forested and soil mantled, with a semiarid climate and a strong precipitation gradient from the Sierra Nevada mountain range to the drier Central Valley of California [Hurst et al., 2012]. The mean annual precipitation is around $1650 \mathrm{~mm}$ and the mean annual temperature is $12.5^{\circ} \mathrm{C}$ [National Climatic Data Center and National Oceanic and Atmospheric Administration (NCDC/NOAA)].

During the Pleistocene, the uppermost sections of the catchment underwent glaciation, whereas the lower areas remained mainly unaffected [Clark, 1995]; our mapping was conducted exclusively in subcatchments unaffected by glaciers. The underlying geology consists of a series of granite, granodiorite, and tonalite plutons (part of the Sierra Nevada batholith) that were emplaced during Cretaceous arc volcanism [Unruh, 1991]. This surface was then dissected by the Feather River, forming deep canyons. This incision is evident from the slope distribution in which the steepest hillslopes are found next to the Feather River and its main tributaries (Figure 1). In turn, this has led to an order of magnitude variation in erosion rates across the landscape, with erosion rates on low-relief surfaces of $<20 \mathrm{~mm} \mathrm{ka}^{-1}$ that contrast with erosion rates in and near the canyon exceeding $200 \mathrm{~mm} \mathrm{ka}^{-1}$ [Riebe et al., 2000; Hurst et al., 2012, 2013]. The distribution of slopes and erosion rates throughout the catchments allows testing of the drainage network extraction algorithms in a landscape of varying topographic form. Two different subbasins of the main Feather River catchment were chosen for analysis in this study: Cascade Ridge and Bald Rock Basin (Figure 1).

\subsection{Wayne National Forest, Ohio}

The second field site used in this study is located in Wayne National Forest, south-eastern Ohio, within the southern, unglaciated Allegheny Plateau (Figure 1). The site remained free of glacial ice during the Pleistocene [Peltier, 2004]. LiDAR data for the site were collected via ALSM mapping by the Ohio Statewide Imagery Program during 2008 and 2009 [OSIP, http://ogrip.oit.ohio.gov/ServicesData/Statewidelmagery/ tabid/86/Default.aspx], with a vertical accuracy of $0.3 \mathrm{~m}$ and a mean horizontal accuracy of $0.3 \mathrm{~m}$.

The forest is divided into three distinct ecoregions: the Marietta Unit, the Athens Unit, and the Ironton Unit [Hix and Pearcy, 1997]. Channel head location data were collected for two catchments in this area: Mid Bailey Run, in the Athens Unit; and Indian Creek, in the Ironton Unit, between 26 May and 7 June 2011. Major flooding in the region had occurred in the month preceding the field mapping. The Athens Unit is the most northerly unit of Wayne National Forest (Figure 1), and has a temperate, continental climate with distinct seasons [Small and McCarthy, 2001]. Precipitation is generally evenly distributed throughout the year, with the wettest month being July and the driest being October. The mean annual precipitation is $1025 \mathrm{~mm}$ and the mean annual temperature is $10.7^{\circ} \mathrm{C}$ [NCDC/NOAA]. The Athens Unit consists of Carboniferous and Permian sediments laid down in shallow seas. These consist of sandstones, shales, siltstones, limestones, and frequent coal seams, which form an eastward-dipping anticline [Goebel and Hix, 1996]. The landscape forms a mature dissected plateau, with moderate to steep slopes, narrow ridges, and stream valleys [Goebel and $H i x, 1996]$. The width of the ridges is strongly controlled by the underlying lithology, with narrow ridges underlain by sandstone and broad ridges underlain by siltstones and shales. Elevations range from 642 to $1044 \mathrm{~m}$ above mean sea level (AMSL). The soils can be classified as moderate-drained to well-drained loam or silt loam soils [Goebel and Hix, 1996]. The Ironton Unit is the most southerly of the districts of the Wayne National Forest (Figure 1). It has similar underlying geology, soil types, and climate to that of the Athens Unit [Martin et al., 2011], and elevations range from 652 to 979 m AMSL.

\subsection{Piedmont, Virginia}

Channel head data in the Piedmont, eastern Virginia (Figure 1), were publicly available online from mapping carried out by Julian et al. [2012]. ALSM was carried out on 40 flight missions between 3 April and 10 May 2011 by Geodigital/Terrapoint, with a vertical accuracy of between 0.083 and $0.101 \mathrm{~m}$ and a mean horizontal accuracy of $0.99 \mathrm{~m}$, and providing a $1 \mathrm{~m}$ resolution DEM. Although additional channel head mapping was carried out by Julian et al. [2012] at other regions across Virginia and West Virginia, freely available LiDAR could not be obtained for these regions.

The Piedmont is a transitional zone between the mountainous regions of the Appalachians to the west, and the Coastal Plain to the east at the Atlantic Ocean (Figure 1). The landscape is forested, with thick, clay-rich soils, and deeply weathered bedrock [Julian et al., 2012]. From November 1946 to April 2012, mean annual 



Figure 2. Field photographs of channel heads mapped in the Feather River, $\mathrm{CA}$ and Wayne National Forest, OH. Red arrow indicates the position of the channel head. (a) Channel head mapped in Bald Rock Basin, CA. (b) Channel head mapped in Mid Bailey Run, OH.

precipitation in the region was $1121 \mathrm{~mm}$, and the mean annual temperature was $13.2^{\circ} \mathrm{C}[\mathrm{NCDC} / \mathrm{NOAA}]$. The Piedmont is made up of Proterozoic to Palaeozoic igneous and metamorphic rocks which form the core of the Appalachians, arranged as a series of distinct terrains separated by thrusts or normal faults [Conley, 1985]. The study area is located within the Fork Mountain Formation which consists of mica schist, biotite gneiss, amphibolite, and quartzite [Conley, 1985]. The topography of the study area is characterized by rolling plains, with moderate relief.

\section{Methods}

\subsection{Field Mapping of Channel Heads}

Field mapping of channel heads was carried out in the Feather River, California in June 2012. A channel head was defined as "the upslope limit of erosion and concentration of flow within steepened banks," following Montgomery and Dietrich [1989]. We determined this upslope limit using features such as sediment sorting, alignment of pine needles, bedrock polishing, and the overall valley shape. Channel heads were then mapped using a Garmin GPS 60 with an average spatial accuracy of $6 \mathrm{~m}$. The particular characteristics of each channel head were noted, and photographs were taken upstream and downstream of the location. Positions of the upstream limit of concentration of flow were taken and dominant valley features were mapped, including evidence of fluvial bedrock incision, or lack of evidence of fluvial action. In cases where upstream access was restricted due to dense vegetation cover, the furthest accessible point of fluvial activity was mapped. Figure 2 shows annotated field photographs of the features mapped as channel heads in this site. Many of the mapped channel heads were initiated by tree throw or were downstream of colluvial hollows. A total of 15 channel heads were mapped in this area along with seven locations of clear bedrock incision, six locations of valleys with no evidence of fluvial activity, and four valleys with restricted access due to vegetation.

Mapped channel head data were also collected at two sites in Wayne National Forest, Ohio, in May-June 2011. Channel heads were mapped using a Trimble GeoXM GeoExplorer 2008 series GPS with $6 \mathrm{~m}$ accuracy, with the same criteria as at the Feather River site. A total of 53 channel heads were mapped in the Mid Bailey Run catchment and 36 channel heads in the Indian Creek catchment. 
The third set of channel head data was made publicly available by Julian et al. [2012] from the Piedmont region. Their study focused on channel head mapping in forested watersheds, using Google Earth to ensure complete forest cover. Channel heads were mapped using a WAAS-enabled Garmin GPSmap 60CSx. Their identification was based on the definition of Dietrich and Dunne [1993], where channel heads were classified as the furthest upslope location of bed load sorting within definable banks. A total of 63 channel heads were mapped in the Piedmont physiographic province.

\subsection{Processing of DEMs and Field Data}

Bare-earth DEMs with $1 \mathrm{~m}$ resolution were obtained from the National Science Foundation Open Topography Project [www.opentopography.org, Accessed 22 February 2013] for the Feather River catchment (California). Bare earth DEMs were obtained for Indian Creek and Mid Bailey Run (Ohio) from the OSIP program [DEMs are available online at http://ogrip.oit.ohio.gov/ProjectsInitiatives/OSIPDataDownloads.aspx, Accessed 22 February 2013]. A bare-earth DEM with a resolution of 2.5 feet for the Piedmont region was obtained from the Center for Geospatial Analysis at the College of William and Mary [Available online at http://www.wm.edu/as/cga/About/index.php, Accessed 22 February 2013]. This was converted to UTM Zone $18 \mathrm{~N}$ with a resolution of $1 \mathrm{~m}$ using cubic interpolation. The DEMs were filled using the filling algorithm of Wang and Liu [2006]. Flow routing was then performed using the D infinity algorithm [Tarboton, 1997]. The field mapped channel heads were then plotted on the DEM of each site. The varying accuracy of the GPS measurements occasionally caused these channel heads to be located in areas of divergent topography. Therefore, each of the points was manually pinned to the nearest DEM-derived flow accumulation line, guided by field notes and slope maps to constrain the process. This resulted in the movement of channel head locations on average by $8.49 \mathrm{~m}$ in the Feather River, $2.10 \mathrm{~m}$ in Mid Bailey Run, $0.97 \mathrm{~m}$ in Indian Creek, and $3.11 \mathrm{~m}$ in the Piedmont region. A possible reason for the discrepancy is the dense forest cover reducing GPS accuracy, which is a common cause of differences between field-located channel heads and their corresponding GPS coordinates [Jefferson and McGee, 2013].

\subsection{Geometric Techniques of Identifying Channel Heads}

We tested two geometric techniques for identifying channel heads: the method of Passalacqua et al. [2010] and that of Pelletier [2013].

\subsubsection{GeoNet 2.0: MATLAB Drainage Network Extraction Algorithm}

The first method of locating channel heads that was evaluated in this study is GeoNet (version 2.0), which is software based on algorithms developed by Passalacqua et al. [2010]. GeoNet filters the DEM based on anisotropic nonlinear diffusion using a Perona-Malik filter. This filter uses the diffusion equation:

$$
\partial_{t} z(x, y, t)=\nabla \cdot[p(|\nabla z|) \nabla z],
$$

where $z(x, y, t)$ represents the elevation at the location $(x, y)$ and at time $t, \nabla z$ is the gradient, and $p(\nabla z)$ represents the edge-stopping function, which prevents diffusion across channel boundaries [Passalacqua et al., 2010]. Nonlinear filtering allows the smoothing of high-frequency, low-relief noise while enhancing the hillslope-to-valley transition.

Passalacqua et al. [2010] define a channel head as occurring when an erosion threshold has been crossed after which fluvial incision takes place, and their method therefore extracts the channel network rather than the valley network. The channel heads are predicted using a tangential-curvature threshold, illustrated in Figure 3a. However, the drainage network resulting from the use of a curvature threshold often results in a series of disconnected segments. In order to improve the drainage network, the algorithm defines the network by minimizing a cost function which is inversely proportional to threshold curvature and contributing drainage area [Passalacqua et al., 2010]. The GeoNet algorithm therefore requires the input of five userdefined parameters: (i) time of forward diffusion; (ii) a quantile-quantile curvature threshold; (iii) a contributing area threshold; (iv) a DEM smoothing criterion; and (v) a cost function threshold. In this study, the default parameters were used for each of the field sites analyzed. Selection of the appropriate curvature threshold or contributing area threshold parameters requires a priori knowledge of the channel head positions, which undermines the program's ability to predict the locations. Therefore, the same parameters were used for each field site in order to test the success of the algorithm at predicting channel head 

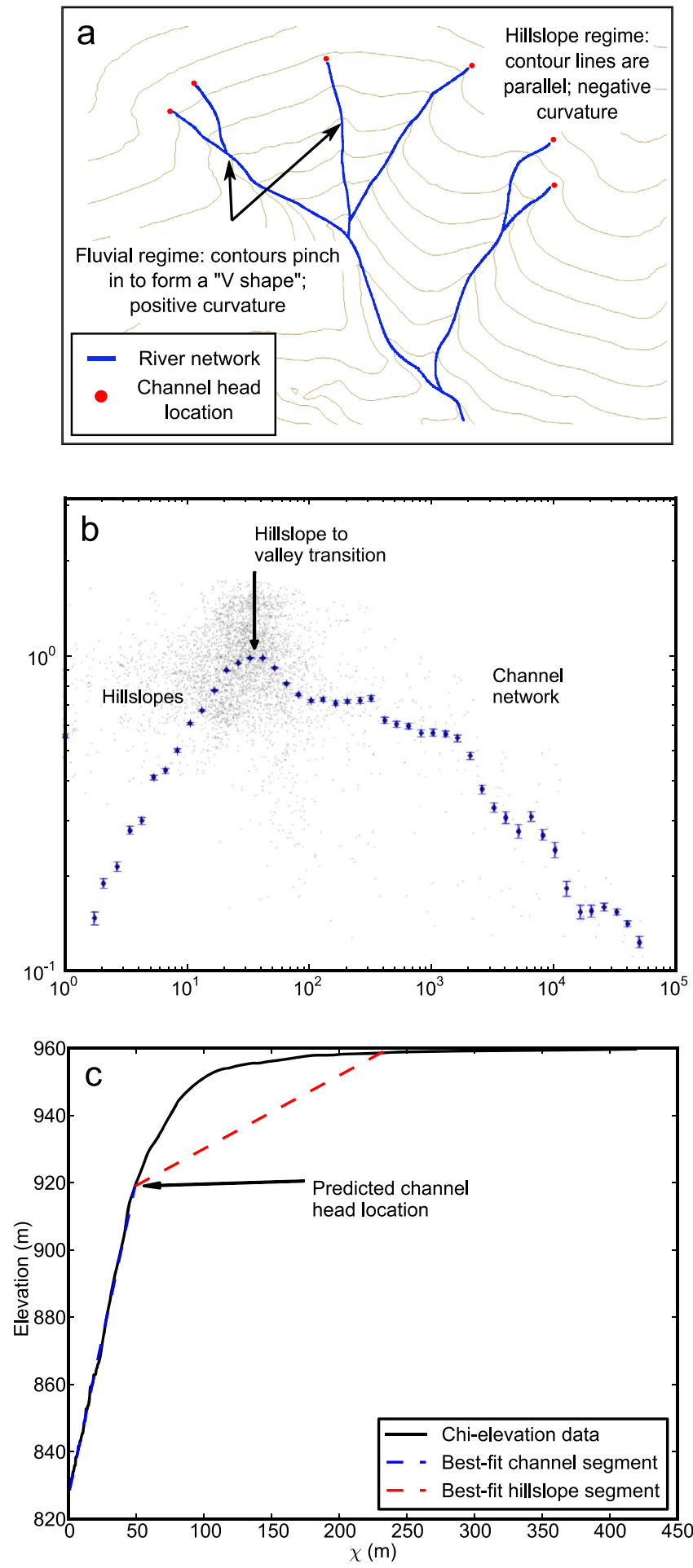

Figure 3. Schematic diagrams of each method showing how they predict channel heads. (a) Both GeoNet 2.0 and the Pelletier method predict channel heads based on tangential curvature, where contour lines form a "V shape" directly below the channel head. (b) The slope-area plot method identifies the transition from fluvial to hillslope scaling forming a "boomerang" shape. The data cloud first must be binned logarithmically (blue). (c) The DrEICH method identifies channel heads based on the transition point between a best fit linear channel segment (blue) and a nonlinear hillslope segment (red). locations across a variety of different landscapes. GeoNet 2.0 was run for each of the field sites, creating a map of the predicted channel head locations and resulting drainage network.

\subsubsection{Pelletier Method}

The second method evaluated for channel head prediction in this study is based on mapping of the landscape tangential curvature, followed by the use of a threshold tangential curvature value, proposed by Pelletier [2013] and illustrated in Figure 3a. This method requires the input of two user-defined parameters, rather than the five parameters used by the GeoNet algorithm. There are three main steps involved in identifying the channel heads from this method, followed by three additional steps to extract the full channel network. As this study focuses on channel head identification, the three principal steps will be described here, but the full method is described in detail by Pelletier [2013]. The first step uses an optimal Wiener filter (OWF) [Wiener, 1949; Press, 2007] to remove highfrequency microtopographic noise by distinguishing the signal of the largescale hillslope-valley morphology and amplifying this signal relative to the noise. The filter uses the transfer function:

$$
\Phi(v)=\frac{|H(v)|^{2}}{|H(v)|^{2}+|N(v)|^{2}},
$$

where $|H(v)|^{2}$ represents the powerlaw radially averaged spectrum which characterizes the large-scale valley morphology, and $|N(v)|^{2}$ represents a flat power spectrum with equal power at all frequencies, characterizing the white noise component. At low frequencies, where $|H(v)|^{2}$ is much greater than $|N(v)|^{2}$, equation (2) approaches unity and the input data are not modified. At high frequencies, where $|N(v)|^{2}$ is greater than $|H(v)|^{2}$, the amplitude of the noise is reduced according to the ratio of the noise to the amplitude of 
the signal. Filtering with an OWF therefore differs from diffusion filtering, in that it does not require any user input as to how much filtering should be performed: the filter weights are instead calculated from the structure of the power spectrum [Press, 2007]. After smoothing the landscape with the OWF, the tangential curvature is mapped: pixels with positive curvature are identified as part of the channel network; while pixels with negative curvature are identified as hillslopes. The tangential curvature $(k)$ is calculated using the following equation, defined by Mitášová and Hofierka [1993]:

$$
k=\frac{z_{x x} z_{y}^{2}-2 z_{x y} z_{x} z_{y}+z_{y y} z_{x}^{2}}{\left(z_{x}^{2}+z_{y}^{2}\right) \sqrt{1+z_{x}^{2}+z_{y}^{2}}}
$$

where $z(x, y)$ represents the elevation, and the subscripts represent derivatives. The final step involves identifying each pixel with a $k$ value higher than that of a user-defined threshold tangential curvature value, $k_{t}$. The valley network may be identified by the transition from negative to positive curvature. Hillslope segments close to the channel network often have positive curvature associated with overland flow, and therefore a low positive threshold value for tangential curvature is more appropriate for determining the start of true channelization [Pelletier, 2013]. Pelletier [2013] tested this algorithm on synthetic valley networks in which the position of the drainage network is known, as well as on two field sites, and suggested that a $k_{t}$ value of $0.1 \mathrm{~m}^{-1}$ produces accurate results for a variety of landscapes. In this study, this suggested value of $k_{t}$ was used to extract the channel head positions from each of the field sites and compared with the field mapped data.

\subsection{Process-Based Techniques of Identifying Channel Heads}

We also tested two process-based techniques: slope-area scaling and the DrEICH method which was developed for this study.

\subsubsection{Slope-Area Scaling Relationships}

Identifying scaling breaks in slope-area plots has traditionally been used to identify channel head locations [Montgomery and Dietrich, 1988]. Many different relationships have been proposed that define a threshold slope and area at which channel initiation occurs [e.g., Montgomery and Dietrich, 1992; Istanbulluoglu et al., 2002]. Jefferson and McGee [2013] suggest that this relationship takes the general form of:

$$
c=A^{\mu} S^{v}
$$

where $c$ represents the threshold value (depending on climate, lithology, vegetation, land use, and soil type), $A$ represents the upslope contributing area (generally in $\mathrm{m}^{2}$ ), and $S$ represents the local slope (typically in $\mathrm{m} / \mathrm{m}$ ). The area exponent $\mu$ is often assumed to be 1 , which allows the normalization of the slope exponent to $v / \mu$, referred to as the relative exponent [Jefferson and McGee, 2013]. This threshold can be identified using slope-area plots, as the different process regimes occurring above and below the threshold result in different relationships between slope and drainage area. Figure $3 \mathrm{~b}$ illustrates the slope-area plot method of identifying channel heads. Where fluvial processes are dominant (below the channel head), slope can be expressed as a power law function of drainage area such that:

$$
S=k_{s} A^{-\theta}
$$

where $S$ is the local slope $(\mathrm{m} / \mathrm{m}), k_{s}$ is the channel steepness index, $A$ is the upslope drainage area $\left(\mathrm{m}^{2}\right)$, and $\theta$ is the concavity index [Flint, 1974].

Where hillslope processes are dominant, gradient increases with drainage area, giving rise to a "boomerang" shape in the slope-area plot [e.g., Roering et al., 2007]. In steep landscapes, however, debris-flow processes may cause a plateau at the transition between hillslope and fluvial processes [Stock and Dietrich, 2006]. This may lead to difficulty in identifying the transition in landscapes with high-erosion rates. In order to test whether this method was successful in predicting channel head locations for the study areas, slopearea plots were constructed for each field site. The slope was calculated based on a polynomial fit with a 
circular window with a radius of $7 \mathrm{~m}$, and the contributing area calculated using the D-infinity flow routing algorithm [Tarboton, 1997]. A window radius of $7 \mathrm{~m}$ was chosen to minimize microtopographic noise influencing local slope on a meter to submeter scale [Roering et al., 2007; Hurst et al., 2012].

Slope and area data for each pixel were sorted into logarithmically spaced bins with a width of 0.1 in logspace, and the standard deviation and standard error of each bin were computed. Graphs of the binned slope-area data were then constructed for each field site to compare the position of the scaling break to the slope and contributing area of the mapped channel heads. Furthermore, the relationship between slope and drainage area between the mapped channel heads was also determined to extract a threshold value (equation (4)). A first set of threshold values were extracted from the mapped channel heads by averaging the contributing area of the mapped channel heads for each field site (setting $\mu$ as 1 and $v$ as 0 in equation (4), referred to as a threshold value of $A$ ). Other analysts have suggested that a threshold based on both slope and contributing area for channel identification may be calculated by setting $\mu$ as 1 and $v$ as 2 in equation (4) [Orlandini et al., 2011], referred to as a threshold value of $A S^{2}$. These threshold values were then used to predict the channel head locations across the landscape.

\subsubsection{DrEICH Method}

The last method of predicting channel head locations is a new algorithm presented in this study based on transformation of river long profiles. This algorithm has two principal stages: first, the basins in which the channel heads are to be identified are selected based on the tangential curvature (the geometry of the valley); and second, the exact position of the channel heads within these basins is calculated using the longitudinal profiles of the channels and hillslopes (a process-based method).

Chi transformations involve integrating drainage area along a channel. The method, first proposed by Royden et al. [2000], allows comparison of the steepness of channels, normalized for drainage area, and suffers less from errors and uncertainties in topographic data than slope-area analysis [Perron and Royden, 2013]. The transformed coordinate, $\chi$ (or chi), can be calculated from any topographic data set, but is best understood in the context of the stream power equation [e.g., Howard, 1994], the predictions of which are broadly consistent with observed channel geometries [e.g., Kirby and Whipple, 2012]. The stream power equation is a detachment-limited model that proposes that the fluvial incision rate is proportional to stream power, which represents the energy expenditure of the flow [Sklar and Dietrich, 1998]. It does not describe overland flow in valley bottoms, or sediment transport on hillslopes by processes such as rainsplash and soil creep. The steady state stream power equation results in the following expression for channel slope:

$$
\left|\frac{d z}{d x}\right|=\left(\frac{U}{K}\right)^{\frac{1}{n}} A(x)^{-\frac{m}{n}}
$$

where $z$ represents elevation $[L], x$ is the horizontal upstream distance $[L], U$ is rock uplift rate relative to a reference elevation value $\left[\mathrm{L} \mathrm{T}^{-1}\right], K$ is an erodibility coefficient, $A$ is drainage area $\left[\mathrm{L}^{2}\right]$, and $m$ and $n$ are constants. Integrating equation (6) leads to the following equation for a river profile, if spatially constant uplift rates and erodibility are assumed:

$$
z(x)=z\left(x_{b}\right)+\left(\frac{U}{K}\right)^{\frac{1}{n}} \int_{x_{b}}^{x} \frac{d x}{A(x)^{\frac{m}{n}}},
$$

where the integration is performed in the upstream direction from the base level $x_{b}$ to the observation point $x$ [Perron and Royden, 2013]. It is performed in the upstream direction to allow integration through tributary junctions, as the tributaries will have the same elevation as the main stem at their confluence. $\mathrm{A}$ reference drainage area $\left(A_{0}\right)$ is then introduced in order to create profiles with units of length on both axes, leading to:

$$
z(x)=z\left(x_{b}\right)+\left(\frac{U}{K A_{0}{ }^{m}}\right)^{\frac{1}{n}} \chi,
$$

where the longitudinal coordinate chi, $\chi$, is given by: 


$$
\chi=\int_{x_{b}}^{x}\left(\frac{A_{0}}{A(x)}\right)^{\frac{m}{n}} d x .
$$

Perron and Royden [2013] plot equation (8) as a line, where the independent variable is $\chi$ and the dependent variable is $z$, both with units of distance. The gradient of the line is represented by $(U / K)^{1 / n} / A_{0}^{m / n}$ and the $y$-intercept by $z\left(x_{b}\right)$. A river profile represented by a plot of $z$ against $\chi$ is referred to as a "chi-plot" $[P e r-$ ron and Royden, 2013]. The ratio $\mathrm{m} / \mathrm{n}$ can be constrained using this method by performing statistical tests to determine the ratio that best linearizes profile data [Perron and Royden, 2013; Mudd et al., 2014].

In this study, chi-plots are used to predict the channel head locations with an algorithm that assumes that the chi-plot is composed of two different segments: a channel segment and a hillslope segment. The channel head is predicted to occur at the transition point between these two segments (Figure $3 \mathrm{c}$ ). The relationship between $z$ and $\chi$ is assumed to be linear in the fluvial segment, where channels conform to the stream power law. However, in the divergent hillslope segment the relationship is nonlinear, due to the change in process regime.

Before the DrEICH algorithm can be used, the best fit $m / n$ value must be obtained for the field site in question, as shown by equation (9). This value is found using routines presented in Mudd et al. [2014]. These routines loop through the potential $\mathrm{m} / \mathrm{n}$ values and perform a linear regression on the chi profile for each value. For each regression, the Akaike information criterion $(A / C)$ is calculated [Akaike, 1974], which is a measure of how well the data fits the linear regression, while penalizing overfitting. The best fit $\mathrm{m} / \mathrm{n}$ is assumed to be the value with the lowest $A / C$ value.

In order to locate basins for channel head identification, we identify concave portions of the landscape based on a methodology for drainage network extraction created by Peucker and Douglas [1975] and described by Band [1986]. Valleys are identified if the stretch of landscape is at least $10 \mathrm{~m}$ long and has a tangential curvature of at least $0.1 \mathrm{~m}^{-1}$, which is the same threshold value used by Pelletier [2013]. We use this tangential curvature threshold value to distinguish between the stream network and threshold hillslopes, as the latter may have a small positive curvature associated with overland flow [Pelletier, 2013; Furbish and Roering, 2013]. The chi segment fitting algorithm is then run from each of the first-order valley outlets identified by the tangential curvature to the hilltop.

Following identification of suitable basins, the valley outlet to hilltop profile is transformed into $\chi$-elevation space. The algorithm then loops through the possible combinations of channel and hillslope segment lengths and performs a linear regression on each segment. This allows the calculation of both the $R^{2}$ value for the linear regression and the Durbin-Watson statistic. The Durbin-Watson statistic $(d)$ is a test for autocorrelation between residuals from the regression analysis [Durbin and Watson, 1950]. The value of $d$ always lies between 0 and 4; if $d$ is $>2$, there is statistical evidence that the residuals correspond to a linear fit; if $d$ is $<2$, then the data are nonlinear. Within the chi-plot, the channel segment should be linear, and thus have a high value of $R^{2}$, whereas the hillslope segment should be nonlinear, and therefore have a low value of $d$. For each combination of segment lengths, a test value $t$ was calculated using these two statistics such that:

$$
t=R_{\text {chan }}^{2}-\frac{d_{\text {hill }}-2}{2}
$$

where $R_{\text {chan }}^{2}$ is the $R^{2}$ value of the channel segment, and $d_{\text {hill }}$ is the Durbin-Watson statistic of the hillslope segment. If $d_{\text {hill }}$ is low, then $\left(d_{\text {hill }}-2\right) / 2$ will be negative. If $d_{\text {hill }}$ is greater or equal to 2 , then $\left(d_{\text {hill }}-2\right) / 2$ will be positive. The second term allows comparison across the two different statistics: $R^{2}$, which varies between 0 and 1 ; and $d$ which values between 0 and 4 . The maximum value of $t$ will occur with a highly linear channel segment and a nonlinear hillslope segment, with $t$ varying between 2 and -1 . This defines the predicted position of the channel head, from which flow routing generates the channel network. This method therefore provides a process-based technique for identifying the onset of fluvial incision. This channel network is distinct from the valley network, which includes all areas of topographic convergence.

\subsection{Comparison of Predictions to Field Data}

For each of the four different methods tested in this study (two geometric techniques and two processbased techniques), the predicted channel heads were compared to the field-mapped locations, with the 
horizontal distance between the predicted and mapped locations noted for each channel head. The mean distance and standard deviation were also calculated for each of the field sites.

We also assessed the ability of the four methods to accurately predict the number of channel heads in a landscape. Three analyses of the quality of each of the methods were carried out in order to test the number of extracted channel heads. These analyses require every channel head in the basin to be mapped and were performed on three basins in Indian Creek, eight basins in Mid Bailey Run, and three basins in the Piedmont. Difficulty with the terrain and dense thickets of Toxicodendron diversilobum (common name: poison oak) and other woody shrubs in the Feather River meant it was not possible to map every channel head in the catchment. Predictions of channel head locations can be divided into three classes: true positives (TP), false positives (FP), and false negatives (FN) [Orlandini et al., 2011]. TPs are defined as occurring when a predicted channel head is found in the same first-order basin as a mapped channel head. FPs occur when a predicted channel head is located in a first-order basin with no mapped channel head. FNs occur when a channel head is not predicted in a first-order basin where there is a mapped channel head. In order to quantify the ability of a method to accurately predict channel head locations, the reliability and sensitivity indices of Orlandini et al. [2011] were used. The reliability of a method can be defined as:

$$
r=\frac{\sum T P}{\sum T P+\sum F P},
$$

where $\Sigma T P$ and $\Sigma F P$ are the total numbers of true and false positives [Orlandini et al., 2011]. This measures the method's capacity not to generate FPs. The sensitivity of a method can be defined as:

$$
s=\frac{\sum T P}{\sum T P+\sum F N}
$$

where $\Sigma T P$ and $\Sigma F N$ are the total numbers of true positives and false negatives. This measures the method's ability not to generate FNs, or to predict all mapped channel heads [Orlandini et al., 2011].

A third analysis was also performed by calculating the drainage density of each basin from the observed channel heads, and comparing this with the drainage density predicted from each of the methods. The drainage density can be defined as the total length of channels within the basin divided by the basin area, and is an essential parameter for hydrologic modeling. A FP located at the downstream end of the firstorder basin will have less impact on the drainage density than a FP at the upstream end of the basin. The percentage error between the mapped and predicted drainage densities for each catchment $\left(\varepsilon_{D D}\right)$ was calculated by:

$$
\varepsilon_{D D}=\left(\frac{D D_{m}-D D_{p}}{D D_{m}}\right) 100
$$

where $D D_{m}$ represents the mapped drainage density and $D D_{p}$ represents the predicted drainage density. The mean $\varepsilon_{D D}$ for each field site was then computed.

\subsection{Sensitivity Analysis}

All the channel network extraction methods tested here require user-defined parameters, the value of which may influence the position of the resulting channel heads. A robust method which is applicable across a range of different landscapes should ideally have as few user-defined parameters as possible. Furthermore, the sensitivity of the results to these parameters is an important factor that must be considered. In order to test the sensitivity of the methods to the parameters chosen, we varied the main parameters for the GeoNet algorithm, the tangential curvature mapping, and the chi analysis for the Indian Creek field site in Ohio. Although GeoNet has five user-defined parameters, the main parameter that influences the position of the channel heads in the GeoNet algorithm is the contributing area parameter. The default value in the program is set to $3000 \mathrm{~m}^{2}$. Additional runs were performed with a contributing area value of both 1000 and $5000 \mathrm{~m}^{2}$ to test the effect on the channel head locations. The tangential curvature mapping algorithm proposed by Pelletier [2013] uses only two user-defined parameters, the most influential of which we 


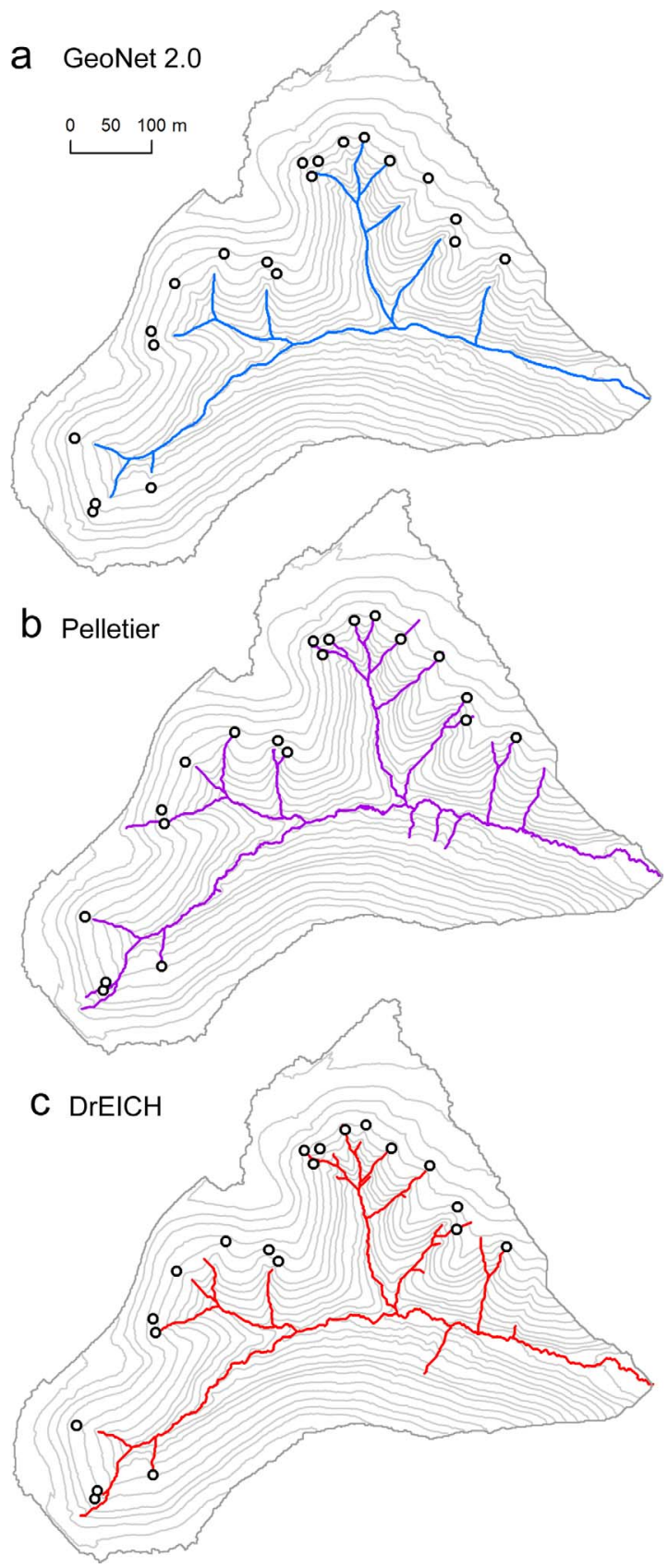

Figure 4. Contour maps showing the results of each method for a catchment in Indian Creek, OH. The circles indicate the field mapped channel heads and the contour intervals are $10 \mathrm{~m}$. (a) Stream network resulting from GeoNet 2.0 shown in blue. (b) Stream network resulting from Pelletier method shown in purple. (c) Stream network resulting from $\mathrm{DrEICH}$ method shown in red. hypothesized to be the tangential curvature threshold $k_{t}$, which determines the pixels selected as channel heads before flow routing. The second user-defined parameter of Pelletier's [2013] method is the discharge per pixel used to connect discontinuous valley segments. Pelletier [2013] suggests that a value of $k_{t}=0.1 \mathrm{~m}^{-1}$ is appropriate across a variety of landscapes, whereas other workers have suggested using a multiple of the standard deviation of contour curvature $(\sigma)$ as the threshold value, as this can be extracted directly from the DEM [Tarolli and Dalla Fontana, 2009]. Therefore, additional runs were performed using a threshold value of $2 \sigma$ and $3 \sigma$ to determine the effect on channel head locations. The chi analysis methodology proposed in this study requires two user-defined parameters: the $m / n$ value, which can be estimated statistically using independent routines created by Mudd et al. [2014] and the number of linked pixels used for valley identification. These user-defined parameters can be determined directly from the DEM alone and do not need to be calculated based on observed channel head locations. Whipple and Tucker [1999] suggest that for most channels, $\mathrm{m} / \mathrm{n}$ falls within a range of $0.35-0.6$, although values of up to 0.79 have been reported [Anthony and Granger, 2007]. In order to test the sensitivity of the algorithm, the $\mathrm{m} / \mathrm{n}$ value was altered from 0.525 (the value suggested by the statistical test) to 0.425 and 0.625 . The number of linked pixels required before a valley is identified may also impact the results of the channel head identification: if this value is too small, the resulting channel network will be feathered; whereas if this value is too large, firstorder tributaries may be missed by the algorithm. Therefore, a sensitivity analysis was performed by varying the number of linked pixels used as a threshold value between 5 and 25 pixels.

\section{Results}

\subsection{Geometric Techniques}

Figure 4a shows channel head locations calculated using the GeoNet 2.0 algorithm. The mean and standard deviation of the horizontal distance between measured and predicted channel heads was calculated for each field site to assess the accuracy of channel head predictions (Figure 5). In some cases, GeoNet did not identify a valley in which a channel head had been mapped. This occurred in 22 tributaries out of the 53 with mapped channel heads in Mid Bailey Run, and in 14 out of 36 in Indian Creek. No tributaries with mapped channel heads were missed in the Feather River or Piedmont field sites. In general, the GeoNet algorithm predicted the channel head location well in Mid Bailey Run and Indian Creek (with a mean distance between mapped and predicted channel heads of 22 and $18 \mathrm{~m}$, respectively), but was less 

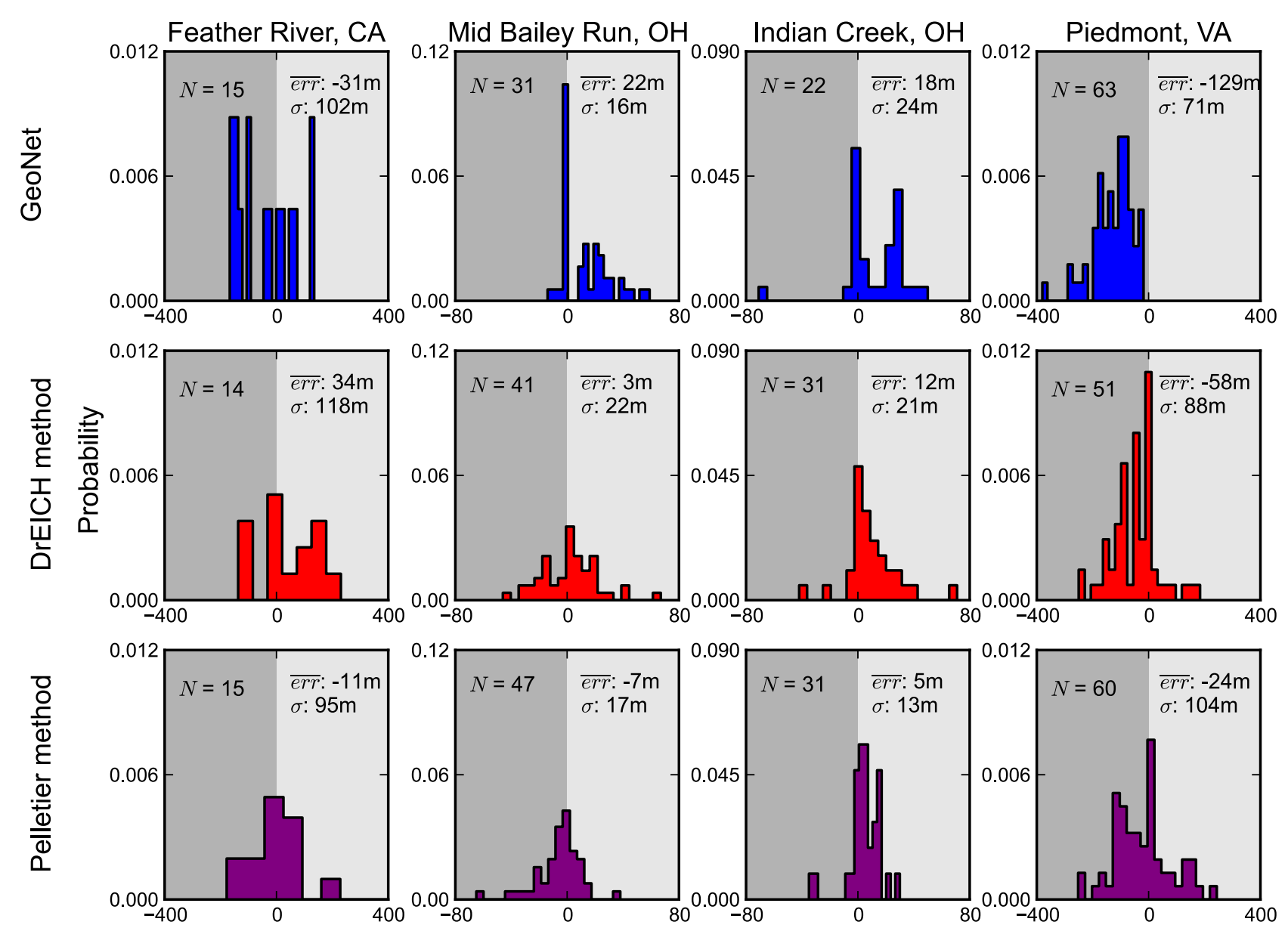

Error between predicted and mapped channel heads $(\mathrm{m})$

Figure 5. Histograms showing the distance and direction of error between the mapped and predicted channel heads for each field site and method. The GeoNet 2.0 software is shown in blue; the DrEICH method is shown in red; and the Pelletier method is shown in purple. The dark gray shading represents areas where the predicted channel heads were located upstream of the mapped (negative); the light gray shading represents areas where the predicted were downstream of the mapped channel heads (positive). The mean and standard deviation of the error are also shown.

accurate in the Feather River $(-31 \mathrm{~m})$ and the Piedmont region $(-129 \mathrm{~m})$. The predicted channel heads were mainly downstream of the mapped positions in the two Ohio field sites, upstream of the mapped positions in the Piedmont, and varied in the Feather River.

Channel head locations from the Pelletier method were predicted using a threshold tangential curvature value of $0.1 \mathrm{~m}^{-1}$, as described in section 3.5. Figure $4 \mathrm{~b}$ shows the drainage network created with the Pelletier algorithm, along with its relationship to the mapped channel heads. In general, the Pelletier method was extremely successful in predicting the channel head locations. The mean distance between the mapped and predicted channel heads was $-11 \mathrm{~m}$ in the Feather River, $-7 \mathrm{~m}$ in Mid Bailey Run, $5 \mathrm{~m}$ in Indian Creek, and $-24 \mathrm{~m}$ in the Piedmont. The predicted channel heads were located upstream of the mapped channel heads at every field site, with the exception of from Indian Creek (Figure 5).

Channel heads could not always be mapped using the Pelletier method if they were located in valleys which did not exceed the curvature threshold. This occurred in six tributaries out of the 53 with mapped channel heads in Mid Bailey Run, five out of 36 in Indian Creek, and three out of 63 in the Piedmont. No tributaries with mapped channel heads were missed in the Feather River.

\subsection{Process-Based Techniques}

Slope-area plots at our field sites indicate that slope-area scaling relationships are generally a poor predictor of the location of the mapped channel heads (Figure 6). For the Cascade Ridge, Mid Bailey Run, and Indian 


\section{QAGU Water Resources Research}
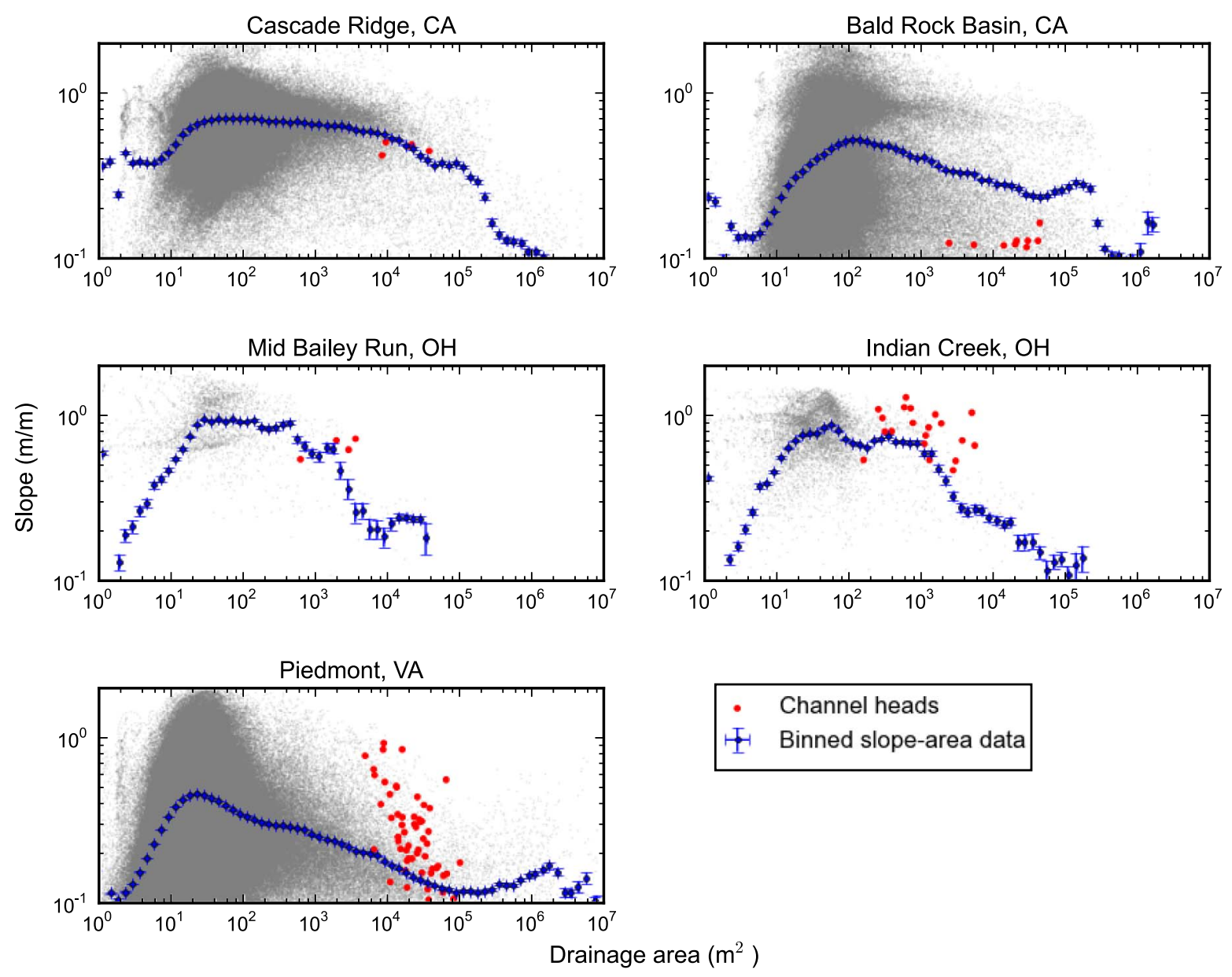

Figure 6. Slope-area plots for each field site. The log-binned slope-area data are shown in blue (with $95 \%$ confidence interval) with a bin width of 0.1 ; the data cloud with every pixel included is shown in gray, and the field mapped channel heads are shown in red. The data clouds were thinned for visualization (every 10 th pixel was selected).

Creek field sites, channel heads are located at a lower drainage area than the point of transition into fluvial scaling where slope decreases with increasing drainage area (Figure 3b). In Bald Rock Basin, the channel heads have a much lower gradient than the mean for the binned data, and in the Piedmont region the channel heads occur within the fluvial scaling regime.

Figure 7 shows the average contributing area and gradient of the channel heads at each location. For each of the field sites, a power law regression was performed on the contributing area and gradient of the channel heads. The $R^{2}$ values of these regressions were 0.0009 for the Feather River, 0.0391 for Mid Bailey Run, 0.1342 for Indian Creek, and 0.1196 for Virginia. Contrary to other studies [Montgomery and Dietrich, 1992; Istanbulluoglu et al., 2002; Jefferson and McGee, 2013], which state that there is a threshold for channel head initiation (based on equation (1)), we find no statistically significant relationship between the slope and drainage area of the mapped channel heads, implying that a slope-area threshold is not effective in identifying channel head locations. Threshold values of $A$ and $A S^{2}$ were also tested to determine their success at predicting channel head locations across the field sites. The average thresholds for these two methods, respectively, for the field sites were: 12,262 and $1805 \mathrm{~m}^{2}$ for the Feather River; 413 and $278 \mathrm{~m}^{2}$ for Mid Bailey Run; 1035 and $640 \mathrm{~m}^{2}$ for Indian Creek; and 20,816 and $1721 \mathrm{~m}^{2}$ in Virginia. The $A$ threshold resulted in errors between the mapped and predicted channel heads of $-39 \mathrm{~m}$ in the Feather River, $-26 \mathrm{~m}$ in Mid Bailey Run, $-26 \mathrm{~m}$ in Indian Creek, and $-94 \mathrm{~m}$ in Virginia. The $A S^{2}$ threshold resulted in errors of $-51,-29$, -18 , and $-65 \mathrm{~m}$ for the same field sites.

The $m / n$ ratio for each of the field sites for use with the DrEICH method was constrained using the routines of Mudd et al. [2014]. This was estimated to be 0.3 for the Feather River, 0.525 for each of the sites in Ohio, 


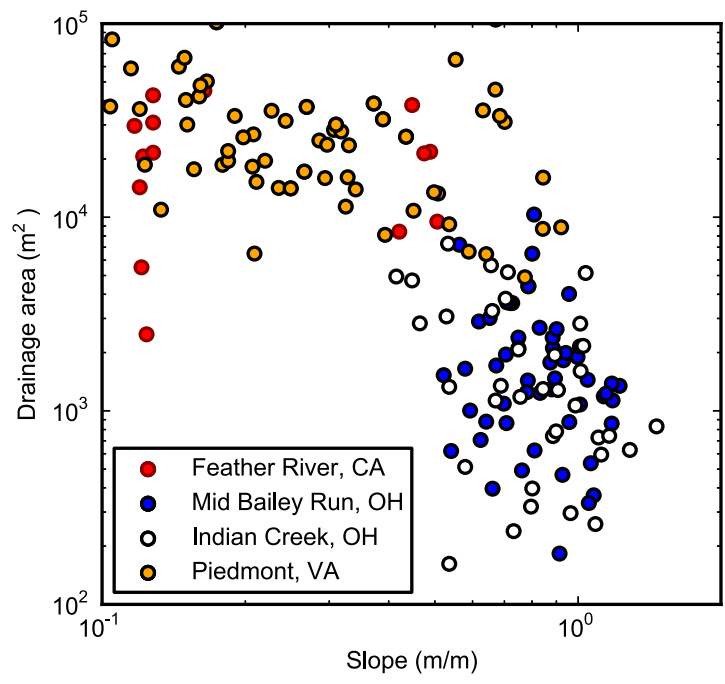

Figure 7. Relationship between slope and drainage area in log space for the mapped channel heads at each field site. There is no clear inverse relationship between slope and drainage area. and 0.375 in Virginia. Figure 8 shows examples of chi-plots for the Indian Creek field site. The linear regressions of the fitted channel and hillslope segments were also plotted in order to identify the predicted channel head location, as well as the corresponding field-mapped channel head. Figure $4 c$ shows the resulting drainage network for the Indian Creek field site. In some cases, a basin with a mapped channel head could not be analyzed due to the valley extraction algorithm threshold used in this study, which only identified valleys with $>10$ linked pixels with a tangential curvature $>0.1 \mathrm{~m}^{-1}$. Such small valleys prevented the analysis of: one channel head in the Feather River, nine out of 53 channel heads in Mid Bailey Run, 10 out of 36 in Indian Creek, and 13 out of 63 channel heads in the Piedmont region. The mean distance between mapped and predicted channel heads was $-12 \mathrm{~m}$ in the

Feather River, $3 \mathrm{~m}$ in Mid Bailey Run, $12 \mathrm{~m}$ in Indian Creek, and $-58 \mathrm{~m}$ in the Piedmont.

A comparison of the results from the three methods (Figure 5), excluding the slope-area analysis, indicates that Pelletier's [2013] tangential curvature method and the DrEICH method were the most successful at locating the channel heads as mapped in the field. The distribution of errors was generally similar in each
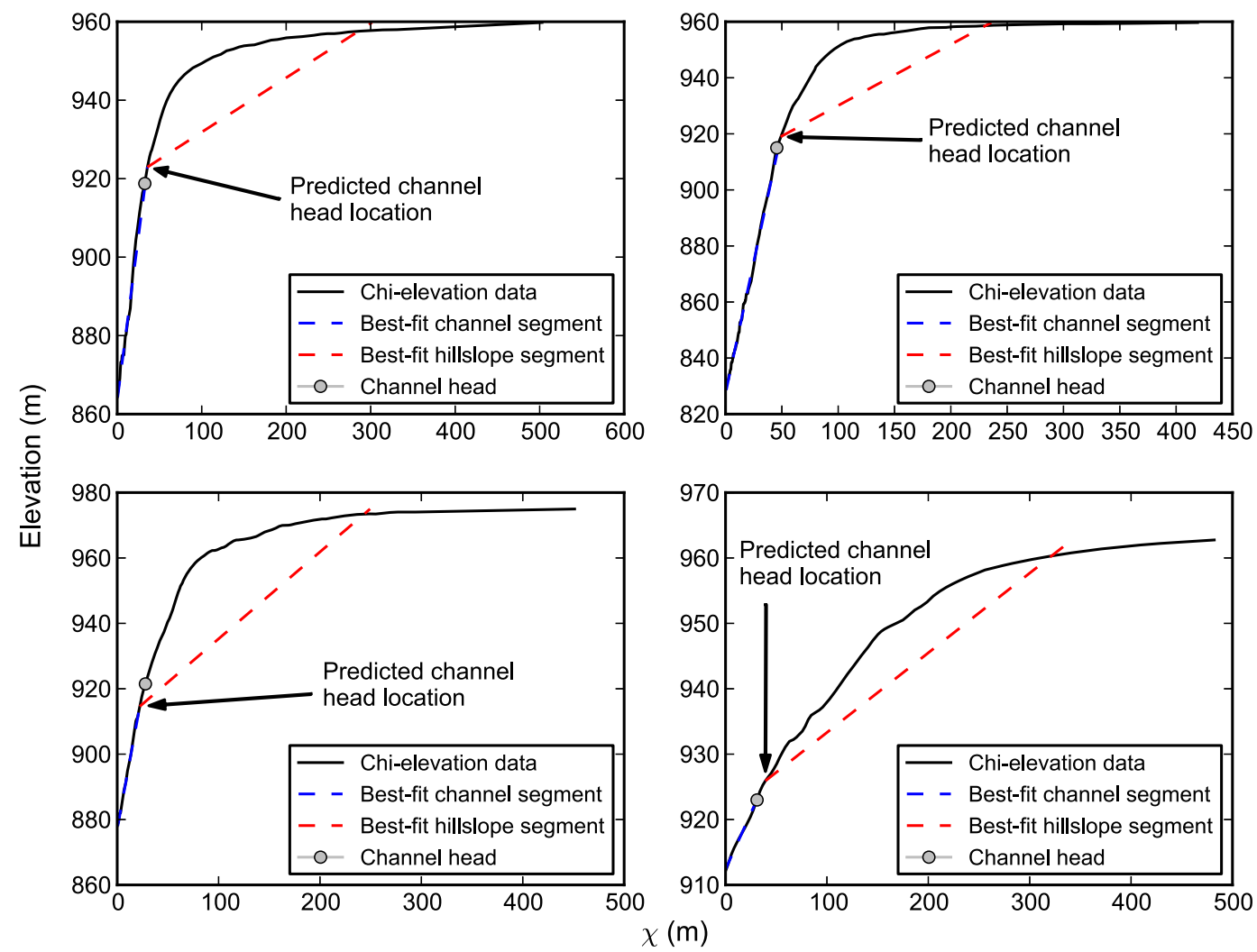

Figure 8. Example chi plots for basins with mapped channel heads in Indian Creek, $\mathrm{OH}$. The transformed river profile is shown in black with the location of the field-mapped channel head shown in gray. The blue line represents the best fit channel segment and the red line represents the best fit hillslope segment, with the transition point between them identifying the predicted location of the channel head. 


\begin{tabular}{|c|c|c|c|c|c|c|c|c|c|}
\hline \multirow[b]{2}{*}{ Field Site } & \multicolumn{3}{|c|}{ GeoNet 2.0} & \multicolumn{3}{|c|}{ DrEICH } & \multicolumn{3}{|c|}{ Pelletier } \\
\hline & $r$ & $s$ & $\varepsilon_{D D}$ & $r$ & $s$ & $\varepsilon_{D D}$ & $r$ & $s$ & $\varepsilon_{D D}$ \\
\hline Mid Bailey Run & 0.727 & 0.453 & -204.84 & 0.489 & 0.830 & -48.17 & 0.520 & 0.736 & -26.05 \\
\hline Indian Creek & 0.783 & 0.500 & 2.70 & 0.509 & 0.750 & -17.38 & 0.531 & 0.722 & -37.60 \\
\hline Piedmont & 0.245 & 1.000 & -138.67 & 0.306 & 0.756 & -64.24 & 0.324 & 0.800 & -47.14 \\
\hline
\end{tabular}

${ }^{a} r$ is the reliability index, $s$ is the sensitivity index, and $\varepsilon_{D D}$ is the error between the mapped and predicted drainage densities (\%).

case, both in terms of magnitude and direction, with Pelletier's [2013] method generally producing the smallest errors across the field sites. This suggests that these two techniques identify similar features as channel heads despite completely different methodologies. In comparison, the errors associated with GeoNet were typically larger, with the exception of the Feather River site, at which the results were comparable to those of the DrEICH method.

\subsection{Analysis of Quality}

Three analyses of the quality of each method were performed as described in section 3.5. The reliability index describes the method's ability not to predict false positives, whereas the sensitivity index describes the method's capacity not to allow false negatives [Orlandini et al., 2011]. The average error between the mapped and predicted drainage density for each of the field sites was also calculated. Negative values indicate that the predicted drainage density was greater than the mapped drainage density. The values of these indices for each of the field sites are reported in Table 1.

\subsection{Sensitivity Analysis}

Sensitivity analyses were performed as described in section 3.6. Figure 9 shows the results of the sensitivity analysis for the Indian Creek field site after altering the parameters for the GeoNet algorithm, the Pelletier algorithm, and the DrEICH algorithm. The GeoNet algorithm is relatively sensitive to changing the contributing area threshold, with the mean error between the mapped and predicted channel heads changing from $18 \pm 24 \mathrm{~m}$ downstream of the mapped channel heads with a threshold of $3000 \mathrm{~m}^{2}$, to $1 \pm 29 \mathrm{~m}$ upstream with a threshold of $1000 \mathrm{~m}^{2}$, to $39 \pm 15 \mathrm{~m}$ downstream with a threshold of $5000 \mathrm{~m}^{2}$. The Pelletier algorithm is less sensitive to changing parameters, although it results in a mean error change from $5 \pm 13 \mathrm{~m}$ downstream with $k_{t}=0.1$, to $6 \pm 15 \mathrm{~m}$ downstream with $k_{t}=2 \sigma_{\mathrm{k}}$ and $15 \pm 10 \mathrm{~m}$ downstream with $k_{t}=3 \sigma_{\mathrm{k}}$. The DrEICH method was found to be relatively insensitive to changing the $m / n$ value. The mean error changes from $12 \pm 21 \mathrm{~m}$ downstream with $\mathrm{m} / \mathrm{n}=0.525$, to $11 \pm 21 \mathrm{~m}$ downstream with $\mathrm{m} / \mathrm{n}=0.425$, to $12 \pm 22 \mathrm{~m}$ downstream with $m / n=0.625$.

The second user-defined parameter used by the DrEICH method is the number of linked pixels used to identify first-order basins (section 3.6.3). Changing this threshold value illustrated that a small threshold value (e.g., $5 \mathrm{~m}$ ) caused the channel network to be "feathered," where the algorithm identified channel heads in small first-order basins that do not exist. However, if the threshold value is too large ( $>20 \mathrm{~m})$, then the algorithm misses some first-order tributaries with mapped channel heads. Therefore, a standard value of $10 \mathrm{~m}$ is suggested when analyzing $1 \mathrm{~m}$ resolution LiDAR with this method, to balance spurious feathering of the network with missing first-order tributaries.

\section{Discussion}

\subsection{Field Mapping of Channel Heads}

Testing methods of drainage network extraction from high-resolution topographic data require mapping of channel heads in the field; however, the exact location of a channel head in the field may be difficult to determine, and may result in subjectivity between different workers. A channel head may be defined morphologically as "the upslope limit of erosion and concentration of flow within steepened banks" [Montgomery and Dietrich, 1989], but the point at which concentration of flow begins within a channel in the field may be unclear, and more importantly may be inherently transient. Channel head mapping in the Feather River was undertaken using a set of identifying criteria, as described in section 3.1. However, the assimilation of data from the two Ohio field sites and from the Piedmont region [Julian et al., 2012] may have led to 

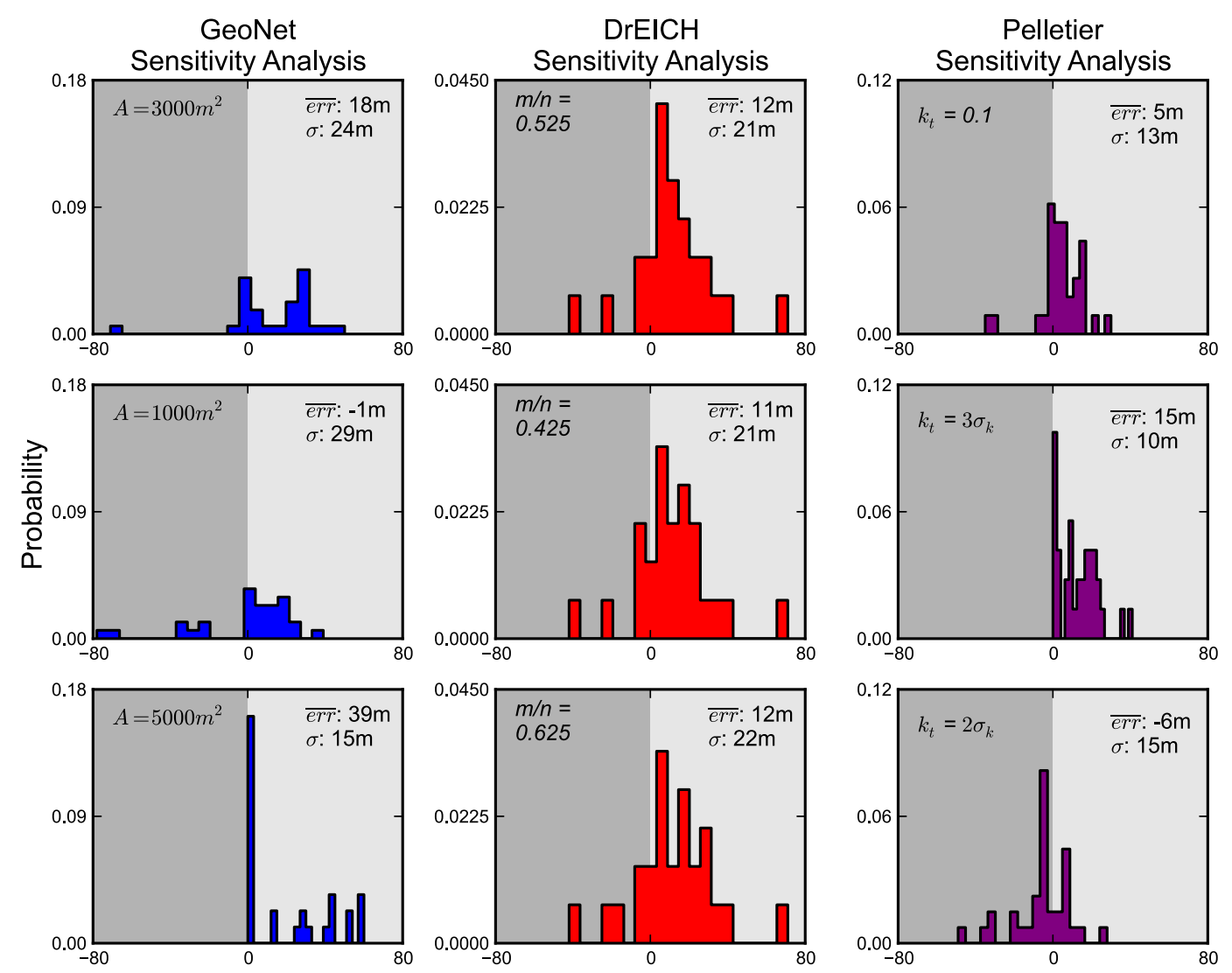

Error between predicted and mapped channel heads $(\mathrm{m})$

Figure 9. Sensitivity analysis for each of the methods at Indian Creek. Each panel shows the value of the parameter than was altered, the resulting mean distance of error between the mapped and predicted channel heads, and the standard deviation. The GeoNet 2.0 method is shown in blue, where the contributing area parameter was changed from 3000 to $1000 \mathrm{~m}^{2}$ and $5000 \mathrm{~m}^{2}$. The DrEICH method is shown in red, where the $\mathrm{m} / \mathrm{n}$ value was changed from 0.525 to 0.425 and 0.625 . The Pelletier method is shown in purple, where the threshold curvature was changed from $0.1 \mathrm{~m}^{-1}$ to multiples of the standard deviation of the curvature.

slight differences in the features being mapped as the channel head. This may be the cause of some error surrounding the channel head locations, and is a recurring problem in mapping of channel heads.

Furthermore, the position of the upstream limit of overland flow will vary temporally depending on many factors [e.g., Dietrich and Dunne, 1993]. Differences in the precipitation volume and intensity (storm frequency) can impact the position of the channel head. We expect that the channel heads would migrate further upstream in years with a high volume of rainfall, and vice versa for years with less rainfall. Changes in vegetation cover, for example due to anthropogenic land use or wildfires, will also influence the partitioning of precipitation into overland flow and thus change the position of the channel head in the field. Evidence of this was observed in the channel heads mapped at the Feather River field site. Channel heads were mapped both in a forested catchment (Cascade Ridge) and a catchment which had recently undergone clearing due to fire (Bald Rock Basin). In general, the channel heads in the cleared catchment were located further up the valley than in the forested catchment. We suggest that the reduction of interception, driven by the reduced canopy extent in the recently burned areas, leads to greater partitioning of precipitation into overland flow, which in turn causes a transient upstream shift of the channel head, which will gradually relax as the canopy recovers.

In contrast, the topographic signatures used to extract channel heads from topographic data (i.e., the longitudinal profile of valleys and hillslopes, or the convergence of topographic contours) represent the timeintegrated balance of hillslope and fluvial sediment transport. Thus, the channel heads predicted from these methods reflect the transition from the hillslope domain to the fluvial domain at timescales significant to landscape evolution. While comparisons to field data should be consistent with prediction of channel heads, and repeating the analysis across multiple landscapes should increase the reliability of the results, 
additional confidence can be gained if different topographic signatures of channel forming processes used by the different methods are consistent in their indication of the location of channel heads.

\subsection{Geometric Techniques}

At the Mid Bailey Run, Indian Creek, and Feather River field sites, the GeoNet algorithm was successful in predicting channel heads within 22, 18, and $-31 \mathrm{~m}$, respectively. However, the error between the predicted and mapped channel heads was greater at the Piedmont field site $(-129 \mathrm{~m})$. Figure 5 shows differences in the direction of error between the field sites. In general, the predicted channel heads were located further downstream than the mapped channel heads in the two Ohio field sites, whereas they were further upstream in the Feather River, and furthest upstream in the Piedmont. This difference between the field sites may be explained by the potential differences in channel head mapping between the sites, as previously discussed. For example, as the channel heads in the Piedmont are further downstream compared to the other field sites, this would suggest that channel heads were systematically mapped further downstream than in the other field sites, corresponding with the results from the slope-area plots. This may be due to the different identification criteria used in comparison with the other sites. GeoNet requires five user-defined parameters in its analysis: time of forward diffusion, a quantile-quantile curvature threshold, a contributing area threshold, a DEM smoothing criterion, and a cost function threshold. In particular, the contributing area parameter may affect the position of the predicted channel heads. As drainage density is inversely proportional to the contributing area upstream of a valley, the predicted stream network will be heavily influenced by the contributing area threshold used in the analysis [Pelletier, 2013].

Figure 9 shows that increasing or decreasing the contributing area threshold moved the location of the predicted channel heads further downstream or upstream, respectively. However, correcting the algorithm for the appropriate value of the parameter requires knowledge of the location of the channel heads in the field. Therefore, this leads to a problem if the drainage network is extracted purely from topographic data with no field information. The quality analysis of the GeoNet 2.0 software showed that this algorithm had a high reliability and lower sensitivity in the two Ohio field sites, suggesting that in these sites few false positives were identified, but many false negatives. This was the opposite in the Piedmont field site, where many false positives were identified but few false negatives. This suggests that the quality of this method varies significantly with field site and would need to be carefully considered when using the GeoNet 2.0 algorithm to extract drainage networks. The drainage density analysis suggested that the GeoNet 2.0 algorithm overpredicted the drainage density significantly in the Mid Bailey Run and Piedmont field sites and underpredicted drainage density slightly in Indian Creek. This is important to take into account when considering flow routing, as a large difference between mapped and predicted drainage densities suggests the predicted channel network may differ significantly from the observed.

The distance of error between the mapped and predicted channel heads when using the Pelletier algorithm was $<25 \mathrm{~m}$ for each of the field sites (Figure 5). The predicted channel heads are generally upstream of the mapped channel heads at each field site, with the exception of Indian Creek, where the predicted channel heads are similar to those identified by the GeoNet 2.0 software. This suggests that this algorithm identifies similar geometric features across the field sites. The quality analysis of the Pelletier algorithm suggested that this method has a higher sensitivity than reliability across the field sites (Table 1), predicting more false positives than false negatives. The drainage density quality analysis shows this method overpredicts drainage density in all locations but provides a more realistic representation of the drainage network than that of the GeoNet 2.0 software.

One of the benefits of this algorithm is the smaller number of user-defined parameters, rather than the five required by the GeoNet 2.0 software. However, the sensitivity analysis performed in this study (Figure 9) suggests that the algorithm is relatively sensitive to the tangential curvature threshold, $k_{t}$. Figure 9 shows that changing the threshold value to $3 \sigma_{\mathrm{k}}$ increases the mean error to $15 \mathrm{~m}$ downstream, while changing the value to $2 \sigma_{\mathrm{k}}$ alters the direction of error, with the mean error changing to $6 \mathrm{~m}$ upstream. The threshold value based on the standard deviation may be more objective, as it uses the geometric properties of the landscape to identify the threshold rather than using the same value for each landscape.

\subsection{Process-Based Techniques}

The comparison of the binned slope-area data from each field site with the slope and drainage area of the channel heads shows that there is no clear relationship between the predicted transition point on the 
slope-area curve and the channel heads (Figure 6). Furthermore, there is no clear inverse relationship between the slope and drainage area of the field-mapped channel heads as would be predicted by the use of a slope-area threshold (Figure 7). Although these relationships have previously been observed [Montgomery and Dietrich, 1988; Tarboton et al., 1992; Montgomery and Foufoula-Georgiou, 1993], these studies generally used DEMs with a resolution of $30 \mathrm{~m}$ or coarser. As the processes involved in channel initiation generally act on a meter to submeter scale, using topographic information from DEMs on this scale to predict channel heads is not reliable [e.g., Orlandini et al., 2011; DiBiase et al., 2012]. Furthermore, the use of slope-area scaling relationships has been shown to be successful in low-relief, soil-mantled landscapes, but in steep landscapes headwater channels are difficult to distinguish from threshold hillslopes when using slope-area plots [Montgomery and Foufoula-Georgiou, 1993]. The recent introduction of higher-resolution DEMs allows these relationships to be examined more robustly. The $A$ threshold and $A S^{2}$ threshold analysis performed on the $1 \mathrm{~m}$ DEMs shows that these methods are less accurate in predicting channel head locations across the landscape than the DrEICH algorithm or the contour curvature technique of Pelletier [2013]. Furthermore, these methods require the presence of field mapped channel heads in order to extract the threshold values, unlike the other methods evaluated in this study.

Figure 6 shows that the channel heads are generally located in the fluvial regime on the slope-area plot, where slope is inversely proportional to drainage area. There is a wide variation of several orders of magnitude in the drainage areas of the mapped channel heads, ranging from 1000 to $1,000,000 \mathrm{~m}^{2}$. Therefore, any method using drainage area to identify channel initiation will be limited because of the uncertainty in the threshold drainage area. Furthermore, the slopes of the mapped channel heads vary between field sites, with the channel heads in Bald Rock Basin occurring at much lower slopes than the binned values or the channel heads from the other field sites. The variation in both the slope and drainage area of the mapped channel heads across the field sites may be due to different processes responsible for channel initiation. Three runoff processes have been suggested to primarily control channel head location: Hortonian or overland flow; the intersection of subsurface flow (e.g., springs) with the land surface; and mass failure [Dietrich and Dunne, 1993]. These processes will occur at different slope angles and drainage areas. This is a key limitation of the slope-area method of predicting channel head locations.

The last method evaluated for channel head prediction was the $\mathrm{DrEICH}$ algorithm, a new method presented in this study. It predicted the channel head locations to within on average $-2 \mathrm{~m}$ in Indian Creek, $-10 \mathrm{~m}$ in Mid Bailey Run, $-34 \mathrm{~m}$ in the Feather River, and $-66 \mathrm{~m}$ in the Piedmont (Figure 5). All predicted channel heads were upstream of the mapped heads. The higher error in the Piedmont data set may again be due to systematic differences in the field mapping strategy between this site and the others. In general, the DrEICH method predicts the channel head locations with less error than the GeoNet 2.0 algorithm and with a similar margin of error compared to the Pelletier method. The quality analysis of the DrEICH algorithm showed that this method has a higher sensitivity index than reliability, suggesting that it is more effective at avoiding false negatives than false positives, similar to the Pelletier algorithm. The drainage density quality validation suggested that the DrEICH algorithm overpredicts drainage density across all of the field sites, similar to the Pelletier algorithm, but provides a more accurate channel network than the GeoNet 2.0 software.

Identifying relationships when using slope-area plots can be extremely difficult due to the impact of lowfrequency noise within the topographic data when slope is estimated [Perron and Royden, 2013]. In order to remove the topographic noise, techniques such as logarithmically binning the data (as used in this study) have to be used. However, although these techniques have been used successfully [Wobus et al., 2006], they introduce bias and uncertainty into the results obtained. The transformation of river profiles into chispace does not suffer from this noise as it does not use an estimate of channel slope [Perron and Royden, 2013]. The DrEICH algorithm is based on the steady-state stream power equation, and therefore can be used when the headwaters of the catchment are undergoing bedrock erosion (detachment-limited). It will not predict channel head locations accurately if the landscape is under transport-limited conditions. However, we would argue that in most upland landscapes where channel heads are initiated, the headwaters will be detachment-limited rather than transport-limited as bedrock incision occurs. In order to obtain a plot of chi vs. elevation for a river channel, an $\mathrm{m} / \mathrm{n}$ ratio must be assigned (see equation (9)). A statistical test to determine the most likely $\mathrm{m} / \mathrm{n}$ ratio can be performed [Mudd et al., 2014]; this test is independent of any field mapping of channel heads. Our results, however, were found to be insensitive to variation in $\mathrm{m} / \mathrm{n}$ 
(Figure 9). The second user-defined parameter in the DrEICH method is the number of linked pixels used to identify first-order basins: a threshold value of $10 \mathrm{~m}$ is suggested in this study.

The mean values and direction of error between the mapped and predicted channel heads are similar between the DrEICH method and the Pelletier method, despite the differences in the approaches. The DrEICH method is based on a theoretical change in process domain from a fluvial segment which obeys the stream power law, to a nonlinear hillslope segment. The Pelletier method, on the other hand, uses a geometrical property of the landscape to identify where the channel heads should occur [Pelletier, 2013]. The general agreement between the two independent methods suggests that we can be confident that these predicted locations truly represent a significant geomorphic feature. Although geometric methods of predicting channel head locations are useful, process-based methods provide a means of examining the fundamental controls on stream initiation. Furthermore, using a process-based method may allow investigation of the factors which determine the length between valley heads and channel heads, yielding insight into the long-term position of process transitions, i.e., between fluvial erosion and hillslope erosion, including diffusion-like and debris flow sediment transport. Therefore, the DrEICH method provides a new, accurate, process-based method which may lead to an increased understanding of the mechanisms governing channel head formation.

\section{Conclusions}

We evaluated different methods commonly used to predict channel head locations from high-resolution topographic data. Traditional methods process-based methods using slope-area scaling relationships or thresholds were less effective than the DrElCH method in all of the field areas. This may be due to the impact of low-frequency topographic noise obscuring the process domain transitions [Perron and Royden, 2013] or the difficulty of distinguishing steep, threshold hillslopes from fluvial channels using slope-area plots [Montgomery and Foufoula-Georgiou, 1993]. Although the GeoNet algorithm predicted channel head locations within $<40 \mathrm{~m}$ for all field sites (excepting the Piedmont field site), it requires a contributing area threshold which must be specified by the user, and the value that is chosen strongly affects the location of the predicted channel heads. An alternative method developed by Pelletier [2013] uses the tangential curvature without a contributing area threshold. Although this method requires two user-defined parameters, most notably the tangential curvature threshold $k_{t}$, it predicted the channel head locations to within a small margin of error at each of the field sites using a standard value of $0.1 \mathrm{~m}^{-1}$. Furthermore, a threshold value of a multiple of the standard deviation [Tarolli and Dalla Fontana, 2009] may provide a method of estimating this tangential curvature threshold directly from DEMs.

The new DrEICH algorithm presented in this study consistently identified the mapped channel head with a small margin of error. This technique requires two user-defined parameters: the $m / n$ value, and the number of linked pixels for valley identification. The sensitivity analysis performed in this study shows that this method is insensitive to changing the $\mathrm{m} / \mathrm{n}$ value. The number of linked pixels affects the density of the resulting stream network, and must be carefully selected in order to use this method.

All techniques tested in this analysis search for a topographic signature of channel heads, and results were compared to channel heads identified in the field. Channel heads identified by human observations can be ambiguous, however, due to subtle differences in the criteria used by different operators to define channel heads, and due to temporal variability in the channel head location induced by, for example, seasonal changes in precipitation or time since last major fire or storm. Furthermore, the coordinates of mapped channel heads may be affected by the accuracy of the GPS device used during field surveying. Despite these uncertainties, the GeoNet, Pelletier [2013], and DrEICH methods all identify channel head locations that are consistent, on the order of tens of meters, with channel heads identified in the field.

We believe that process-based channel head detection methods, such as the DrEICH algorithm, can ultimately be used to examine fundamental aspects of landscape evolution, because they quantify geomorphic process transitions averaged over geomorphic timescales, defined as the time it takes geomorphic processes to reconfigure topography. A number of authors have noted that the valley network is not the same as the channel network [e.g., Dietrich and Dunne, 1993; Rinaldo et al., 1995]. Separation of the extent of the valley network from the extent of the landscape that has a fluvial topographic signature could help determine the formation, stability, and temporal dynamics of the unchanneled portions of the valley network, 
hypothesized to be caused by climate change [e.g., Rinaldo et al., 1995], chemical weathering [e.g., Mudd and Furbish, 2004], or a transition to landslide susceptibility [e.g., Dietrich et al., 1986]. We show that the DrEICH algorithm can produce consistent, objective estimates of channel head locations, and thus can provide reproducible estimates of channel network extent.

\section{Acknowledgments}

F.J.C. is supported by Carnegie Trust for the Universities of Scotland. S.M.M. is supported by NERC grant NE/ J009970/1 and U.S. Army Research Office contract number W911NF-13-10478. D.T.M. is supported by NERC grant NE/J500021/1. L.J.S. was supported by a NERC PhD studentship. We also thank Louis Kinnear for helping to collect the field data, and three anonymous reviews whose comments helped improve the manuscript. DEMs are freely available online as stated throughout the text, and the channel head data used are available at http://datashare.is.ed.ac. uk/handle/10283/431. F.J.C. and S.M.M. designed the DrEICH algorithm. F.J.C., S.M.M., and D.T.M. wrote the software. F.J.C. performed the analyses. F.J.C., M.D.H., and L.J.S. collected the field data. All authors contributed to writing the paper.

\section{References}

Akaike, H. (1974), A new look at the statistical model identification, IEEE Trans. Autom. Control, 19(6), 716-723, doi:10.1109/ tac.1974.1100705.

Anthony, D. M., and D. E. Granger (2007), An empirical stream power formulation for knickpoint retreat in Appalachian Plateau fluviokarst, J. Hydrol., 343, 117-126, doi:10.1016/j.jhydrol.2007.06.013.

Band, L. E. (1986), Topographic partition of watersheds with digital elevation models, Water Resour. Res., 22(1), 15-24, doi:10.1029/ WR022i001p00015.

Clark, D. H. (1995), Extent, timing, and climatic significance of latest Pleistocene and Holocene glaciation in the Sierra Nevada, California, $\mathrm{PhD}$ thesis, Univ. of Washington, Seattle.

Conley, J. F. (1985), Geology of the Southwestern Virginia Piedmont, Va. Div. of Miner. Resour. Publ., Dept. of Mines, Miner. and Energy, Charlottesville, Va.

DiBiase, R. A., A. M. Heimsath, and K. X. Whipple (2012), Hillslope response to tectonic forcing in threshold landscapes, Earth Surf. Processes Landforms, 37(8), 855-865, doi:10.1002/esp.3205.

Dietrich, W. E., and T. Dunne (1993), The channel head, in Channel Network Hydrology, edited by K. Beven and M. J. Kirkby, pp. 175-219, John Wiley, N. Y.

Dietrich, W. E., C. J. Wilson, and S. L. Reneau (1986), Hollows, colluvium and landslides in soil-mantled landscapes, in Hillslope Processes, edited by A. D. Abrahams, pp. 361-388, Allen and Unwin, Winchester, Mass.

Dietrich, W. E., C. J. Wilson, D. R. Montgomery, J. McKean, and R. Bauer (1992), Erosion thresholds and land surface morphology, Geology, 20(8), 675-679, doi:10.1130/0091-7613(1992)020<0675:ETALSM>2.3.CO;2.

Dietrich, W. E., C. J. Wilson, D. R. Montgomery, and J. McKean (1993), Analysis of erosion thresholds, channel networks, and landscape morphology using a digital terrain model, J. Geol., 101(2), 259-278, doi:10.2307/30081151.

Durbin, J., and G. S. Watson (1950), Testing for serial correlation in least squares regression: I, Biometrika, 37(3-4), 409-428, doi:10.1093/biomet/37.3-4.409.

Flint, J. J. (1974), Stream gradient as a function of order, magnitude, and discharge, Water Resour. Res., 10(5), 969-973, doi:10.1029/ WR010i005p00969.

Furbish, D. J., and J. J. Roering (2013), Sediment disentrainment and the concept of local versus nonlocal transport on hillslopes, J. Geophys. Res., 118, 937-952, doi:10.1002/jgrf.20071.

Goebel, P. C., and D. M. Hix (1996), Development of mixed-oak forests in southeastern Ohio: A comparison of second-growth and oldgrowth forests, For. Ecol. Manage., 84(1-3), 1-21, doi:10.1016/0378-1127(96)03772-3.

Henkle, J. E., E. Wohl, and N. Beckman (2011), Locations of channel heads in the semiarid Colorado Front Range, USA, Geomorphology, 129(3-4), 309-319, doi:10.1016/j.geomorph.2011.02.026.

Hix, D. M., and J. N. Pearcy (1997), Forest ecosystems of the Marietta Unit, Wayne National Forest, southeastern Ohio: Multifactor classification and analysis, Can. J. For. Res., 27(7), 1117-1131, doi:10.1139/x97-044.

Howard, A. D. (1994), A detachment-limited model of drainage basin evolution, Water Resour. Res., 30(7), 2261-2285, doi:10.1029/ 94WR00757.

Hurst, M. D., S. M. Mudd, R. Walcott, M. Attal, and K. Yoo (2012), Using hilltop curvature to derive the spatial distribution of erosion rates, J. Geophys. Res., 117, F02017, doi:10.1029/2011JF002057.

Hurst, M. D., S. M. Mudd, K. Yoo, M. Attal, and R. Walcott (2013), Influence of lithology on hillslope morphology and response to tectonic forcing in the northern Sierra Nevada of California, J. Geophys. Res., 118, 832-851, doi:10.1002/jgrf.20049.

Istanbulluoglu, E., D. G. Tarboton, R. T. Pack, and C. Luce (2002), A probabilistic approach for channel initiation, Water Resour. Res., 38(12), 1325, doi:10.1029/2001WR000782.

Jefferson, A. J., and R. W. McGee (2013), Channel network extent in the context of historical land use, flow generation processes, and landscape evolution in the North Carolina Piedmont, Earth Surf. Processes Landforms, 38(6), 601-613, doi:10.1002/esp.3308.

Julian, J. P., A. J. Elmore, and S. M. Guinn (2012), Channel head locations in forested watersheds across the mid-Atlantic United States: A physiographic analysis, Geomorphology, 177-178, 194-203, doi:10.1016/j.geomorph.2012.07.029.

Kirby, E., and K. X. Whipple (2012), Expression of active tectonics in erosional landscapes, J. Struct. Geol., 44, 54-75, doi:10.1016/ j.jsg.2012.07.009.

Martin, K. L., D. M. Hix, and P. C. Goebel (2011), Coupling of vegetation layers and environmental influences in a mature, second-growth Central Hardwood forest landscape, For. Ecol. Manage., 261(3), 720-729, doi:10.1016/j.foreco.2010.12.001.

Mitášová, H., and J. Hofierka (1993), Interpolation by regularized spline with tension: II. Application to terrain modeling and surface geometry analysis, Math. Geol., 25(6), 657-669, doi:10.1007/BF00893172.

Molloy, I., and T. F. Stepinski (2007), Automatic mapping of valley networks on Mars, Comput. Geosci., 33(6), 728-738, doi:10.1016/ j.cageo.2006.09.009.

Montgomery, D. R., and W. E. Dietrich (1988), Where do channels begin?, Nature, 336, 232-234, doi:10.1038/336232a0

Montgomery, D. R., and W. E. Dietrich (1989), Source areas, drainage density, and channel initiation, Water Resour. Res., 25(8), 1907-1918, doi:10.1029/WR025i008p01907.

Montgomery, D. R., and W. E. Dietrich (1992), Channel initiation and the problem of landscape scale, Science, 255(5046), 826-830, doi: $10.1126 /$ science.255.5046.826

Montgomery, D. R., and E. Foufoula-Georgiou (1993), Channel network source representation using digital elevation models, Water Resour. Res., 29(12), 3925-3934, doi:10.1029/93WR02463.

Mudd, S. M., and D. J. Furbish (2004), Influence of chemical denudation on hillslope morphology, J. Geophys. Res., 109, F02001, doi:10.1029/ 2003JF000087.

Mudd, S. M., M. Attal, D. T. Milodowski, S. W. D. Grieve, and D. A. Valters (2014), A statistical framework to quantify spatial variation in channel gradients using the integral method of channel profile analysis, J. Geophys. Res., 119, 138-152, doi:10.1002/2013JF002981. 
Novotny, V. (2002), Water Quality: Diffuse Pollution and Watershed Management, John Wiley, N. Y.

O'Callaghan, J. F., and D. M. Mark (1984), The extraction of drainage networks from digital elevation data, Comput. Vis. Graph. Image Process., 28(3), 323-344, doi:10.1016/S0734-189X(84)80011-0.

Orlandini, S., P. Tarolli, G. Moretti, and G. Dalla Fontana (2011), On the prediction of channel heads in a complex alpine terrain using gridded elevation data, Water Resour. Res., 47(2), W02538, doi:10.1029/2010WR009648.

Passalacqua, P., T. Do Trung, E. Foufoula-Georgiou, G. Sapiro, and W. E. Dietrich (2010), A geometric framework for channel network extraction from lidar: Nonlinear diffusion and geodesic paths, J. Geophys. Res., 115, F01002, doi:10.1029/2009JF001254.

Pelletier, J. D. (2013), A robust, two-parameter method for the extraction of drainage networks from high-resolution digital elevation models (DEMs): Evaluation using synthetic and real-world DEMs, Water Resour. Res., 49, 75-89, doi:10.1029/2012WR012452.

Peltier, W. R. (2004), Global glacial isostacy and the surface of the ice-age Earth: The ICE-5G (VM2) model and GRACE, Annu. Rev. Earth Planet. Sci., 32(1), 111-149, doi:10.1146/annurev.earth.32.082503.144359.

Perron, J. T., and L. Royden (2013), An integral approach to bedrock river profile analysis, Earth Surf. Processes Landforms, 38(6), 570-576, doi:10.1002/esp.3302

Peucker, T. K., and D. H. Douglas (1975), Detection of surface-specific points by local parallel processing of discrete terrain elevation data, Comput. Graph. Image Process., 4(4), 375-387, doi:10.1016/0146-664X(75)90005-2.

Press, W. H. (2007), Numerical Recipes: The Art of Scientific Computing/William H. Press [and Others], Cambridge Univ. Press, Cambridge, U. K.

Riebe, C. S., J. W. Kirchner, D. E. Granger, and R. C. Finkel (2000), Erosional equilibrium and disequilibrium in the Sierra Nevada, inferred from cosmogenic 26Al and 10Be in alluvial sediment, Geology, 28(9), 803-806, doi:10.1130/0091-7613(2000)28<803:EEADIT>2.0.CO;2.

Rinaldo, A., W. E. Dietrich, R. Rigon, G. K. Vogel, and I. Rodrlguez-Iturbe (1995), Geomorphological signatures of varying climate, Nature, 374(6523), 632-635, doi:10.1038/374632a0.

Roering, J. J., J. T. Perron, and J. W. Kirchner (2007), Functional relationships between denudation and hillslope form and relief, Earth Planet. Sci. Lett., 264(1-2), 245-258, doi:10.1016/j.epsl.2007.09.035.

Royden, L. H., M. K. Clark, and K. X. Whipple (2000), Evolution of river elevation profiles by bedrock incision: Analytical solutions for transient river profiles related to changing uplift and precipitation rates, Eos Trans. AGU, 81(48), Fall Meet. Suppl., Abstract T62F-09.

Sklar, L., and W. E. Dietrich (1998), River longitudinal profiles and bedrock incision models: Stream power and the influence of sediment supply, in Rivers Over Rock: Fluvial Processes in Bedrock Channels, edited by K. J. Tinkler and E. E. Wohl, pp. 237-260, AGU, Washington, D. C.

Small, C. J., and B. C. McCarthy (2001), Vascular flora of the Waterloo Wildlife Research Station, Athens County, Ohio, Castanea, 66(4), 363382, doi: $10.2307 / 4033925$.

Sofia, G., P. Tarolli, F. Cazorzi, and G. Dalla Fontana (2011), An objective approach for feature extraction: Distribution analysis and statistical descriptors for scale choice and channel network identification, Hydrol. Earth Syst. Sci., 15(5), 1387-1402, doi:10.5194/hess-15-13872011.

Stock, J. D., and W. E. Dietrich (2006), Erosion of steepland valleys by debris flows, Geol. Soc. Am. Bull., 118(9-10), 1125-1148, doi:10.1130/ B25902.1.

Tarboton, D. G. (1997), A new method for the determination of flow directions and upslope areas in grid digital elevation models, Water Resour. Res., 33(2), 309-319, doi:10.1029/96WR03137.

Tarboton, D. G., R. L. Bras, and I. Rodriguez-Iturbe (1991), On the extraction of channel networks from digital elevation data, Hydrol. Processes, 5(1), 81-100, doi:10.1002/hyp.3360050107.

Tarboton, D. G., R. L. Bras, and I. Rodriguez-Iturbe (1992), A physical basis for drainage density, Geomorphology, 5(1-2), 59-76, doi:10.1016/ 0169-555X(92)90058-V.

Tarolli, P., and G. Dalla Fontana (2009), Hillslope-to-valley transition morphology: New opportunities from high resolution DTMs, Geomorphology, 113(1-2), 47-56, doi:10.1016/j.geomorph.2009.02.006.

Thommeret, N., J. S. Bailly, and C. Puech (2010), Extraction of thalweg networks from DTMs: Application to badlands, Hydrol. Earth Syst. Sci., 14(8), 1527-1536, doi:10.5194/hess-14-1527-2010.

Unruh, J. R. (1991), The uplift of the Sierra Nevada and implications for late Cenozoic epeirogeny in the western Cordillera, Geol. Soc. Am. Bull., 103(11), 1395-1404, doi:10.1130/0016-7606(1991)103<1395:TUOTSN >2.3.CO;2.

Wang, L., and H. Liu (2006), An efficient method for identifying and filling surface depressions in digital elevation models for hydrologic analysis and modelling, Int. J. Geogr. Inf. Sci., 20(2), 193-213, doi:10.1080/13658810500433453.

Whipple, K. X., and G. E. Tucker (1999), Dynamics of the stream-power river incision model: Implications for height limits of mountain ranges, landscape response timescales, and research needs, J. Geophys. Res., 104(B8), 17,661-17,674, doi:10.1029/1999JB900120.

Wiener, N. (1949), Extrapolation, Interpolation, and Smoothing of Stationary Time Series: With Engineering Applications, Technol. Press of the Mass. Inst. of Technol., Cambridge, Mass.

Wobus, C., K. X. Whipple, E. Kirby, N. Snyder, J. Johnson, K. Spyropolou, B. Crosby, and D. Sheehan (2006), Tectonics from topography: Procedures, promise, and pitfalls, Geol. Soc. Am. Spec. Pap., 398, 55-74, doi:10.1130/2006.2398(04). 